\title{
Immunosuppressive network promotes immunosenescence associated with aging and chronic inflammatory conditions
}

\author{
Antero Salminen $^{1}$ (D) \\ Received: 26 April 2021 / Revised: 21 July 2021 / Accepted: 30 July 2021 / Published online: 25 August 2021 \\ (C) The Author(s) 2021
}

\begin{abstract}
The functional competence of the immune system gradually declines with aging, a process called immunosenescence. The age-related remodelling of the immune system affects both adaptive and innate immunity. In particular, a chronic low-grade inflammation, termed inflammaging, is associated with the aging process. Immunosenescence not only is present in inflammaging state, but it also occurs in several pathological conditions in conjunction with chronic inflammation. It is known that persistent inflammation stimulates a counteracting compensatory immunosuppression intended to protect host tissues. Inflammatory mediators enhance myelopoiesis and induce the generation of immature myeloid-derived suppressor cells (MDSC) which in mutual cooperation stimulates the immunosuppressive network. Immunosuppressive cells, especially MDSCs, regulatory T cells (Treg), and M2 macrophages produce immunosuppressive factors, e.g., TGF- $\beta$, IL-10, ROS, arginase-1 (ARG1), and indoleamine 2,3-dioxygenase (IDO), which suppress the functions of CD4/CD8T and B cells as well as macrophages, natural killer (NK) cells, and dendritic cells. The immunosuppressive armament (i) inhibits the development and proliferation of immune cells, (ii) decreases the cytotoxic activity of CD8T and NK cells, (iii) prevents antigen presentation and antibody production, and (iv) suppresses responsiveness to inflammatory mediators. These phenotypes are the hallmarks of immunosenescence. Immunosuppressive factors are able to control the chromatin landscape, and thus, it seems that the immunosenescence state is epigenetically regulated.
\end{abstract}

Keywords Aging $\cdot$ Alzheimer's $\cdot$ Cellular senescence $\cdot$ Immune tolerance $\cdot$ Immunosuppression $\cdot$ Kynurenine

\section{Introduction}

The aging process is associated with a deterioration of the immune system, commonly referred to as immunosenescence. The age-related decline in the functions of immune cells involves both adaptive immunity, such as $\mathrm{T}$ and $\mathrm{B}$ cells, and innate immunity including macrophages as well as dendritic and natural killer (NK) cells $[1,2]$. Concurrently, there exists a chronic low-grade inflammatory state, termed inflammaging (Fig. 1). At present, there is an ongoing debate whether immunosenescence is a cause or a consequence of inflammaging. There is clear evidence that immunosenescence increases the risk for the growth of tumors and a persistent inflammatory state during infections,

Antero Salminen

antero.salminen@uef.fi

1 Department of Neurology, Institute of Clinical Medicine, University of Eastern Finland, P.O. Box 1627, 70211 Kuopio, Finland whereas it seems to improve the efficiency of transplantation [3-5]. Currently, the molecular basis of immunosenescence is unknown, although it is a hallmark of the aging process. Another characteristic of aging is the accumulation of senescent non-immune cells within tissues in both mice and humans [6]. Interestingly, not only inflammaging but also immunosenescence occurs in several pathological conditions associated with chronic inflammation (see below). It is known that persistent inflammation stimulates a counteracting compensatory immunosuppression intended to protect tissue homeostasis [7-9]. Immune cells are highly plastic cells which can display different phenotypes and even be converted into other immune cell types. These flexible processes are most probably under some form of epigenetic regulation (see below). Inflammatory mediators enhance myelopoiesis and trigger the generation of immature myeloid-derived suppressor cells (MDSC) which are able to enhance the immunosuppressive properties of other immune cells [10]. The immunosuppressive phenotypes are called regulatory ones including, e.g., regulatory $\mathrm{T}$ (Treg) 


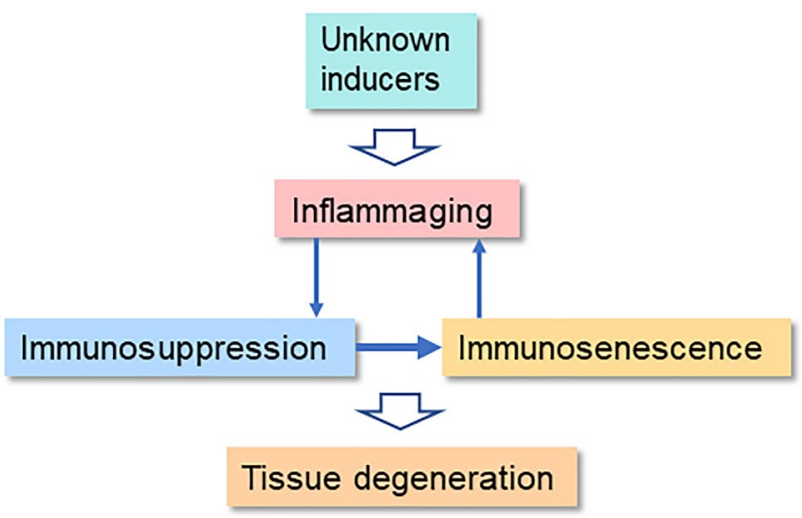

Fig. 1 The feed-forward cycle between inflammaging, immunosuppression, and immunosenescence. Unknown inducers provoke an inflammaging state which stimulates a counteracting compensatory immunosuppression in an attempt to protect the host tissues. The activation of the immunosuppressive network (Fig. 2) induces an immunosenescence state in the effector immune cells. Subsequently, immunosenescence promotes inflammation and aggravates inflammaging in tissues. The chronic presence of both immunosuppression and immunosenescence augments tissue degeneration with aging and inflammatory conditions

and B (Breg) cells. Interestingly, immunosuppressive cells secrete different immunoregulatory factors which inhibit the acute inflammatory responses of effector cells and in that way promote their immunosenescence (Fig. 2). Here, I will examine the generation of immunosenescence, particularly the form encountered in T and NK cells, through the control of immunosuppressive network.

\section{Definition of immunosenescence and exhaustion of immune cells}

The gradual decline of the immune system with aging, i.e., immunosenescence, is an evolutionarily conserved phenomenon. Immunosenescence represents the age-related remodelling of the immune system with aging [1,2]. However, the definition of immunosenescence and its effects on human health with aging are currently under debate [11]. There are several reasons that immunosenescence seems to be an irreversible, context-dependent process, and it is not known whether the changes are beneficial or detrimental. In fact, the cells of the immune system can display some plasticity in their phenotypes. For instance, the $\mathrm{T}$ cell population can express the effector phenotypes (Teff) and immunosuppressive phenotypes, i.e., Treg cells. Accordingly, Tregs can provoke the changes in human $\mathrm{T}$ cells which are reminiscent of those found in immunosenescent T cells [12, 13] (Fig. 2). Moreover, human natural killer (NK) cells undergo a significant differentiation process with aging [14]. Given that the inflammatory microenvironment augments immunosenescence, the occurrence of immunosenescent cells increases in many age-related diseases $[15,16]$. The presence of lowgrade chronic inflammation most probably promotes immunosenescence with aging and thus enhances the inflammaging state through a feed-forward process [17]. Considering the plasticity of immune cells, it seems that there does not exist any specific immunosenescent phenotypes but instead a wide spectrum of immune cells expressing a set of markers of immune senescence. The characteristics of the immunosenescent phenotypes of different immune cells will be examined in detail below.

The age-related involution of the thymus has a profound effect on immunosenescence, especially on the senescence of mouse and human $\mathrm{T}$ cells. Studies on senescent $\mathrm{T}$ cells have revealed a state called $\mathrm{T}$ cell exhaustion which have many different properties compared to those of senescent $\mathrm{T}$ cells $[18,19]$. Chronic infections, autoimmune diseases, and cancers, i.e., the chronic elevation of the antigenic load, induce the phenotype of exhausted T cells, in both CD4 and CD8 $\mathrm{T}$ cells. The exhaustion of Teff cells arrests cell proliferation and induces a hyporesponsive, anergic state which may safeguard against the development of autoimmune diseases. Exhausted T cells do not produce cytokines, whereas senescent $\mathrm{T}$ cells secrete an increased level of pro-inflammatory cytokines. Moreover, the specific hallmark of exhausted T cells is a significant increase in the expression of multiple inhibitory receptors, such as PD-1, CTLA-4, LAG-3, and TIGIT [19]. Wang et al. [20] exploited single-cell transcriptomics to assay the specific properties of exhausted $\mathrm{T}$ cells in the HIV-infected humans. They reported that exhausted CD8 $\mathrm{T}$ cells displayed a strong upregulation of killer cell lectin-like receptor subfamily $\mathrm{G}$ member 1 (KLRG1) in HIV patients. Interestingly, an antibody blockade therapy targeted at the KLRG1 protein significantly restored the function of CD8 T cells in HIV individuals. It is known that a therapy aimed at blocking the PD-1 protein also reinvigorated exhausted $\mathrm{T}$ cells in persistent virus infections and cancers [21]. There are studies indicating that human NK cells can display different dysfunctional states including anergy and exhaustion, in addition to the immunosenescent state [22]. Exhausted NK cells undergo an upregulation of PD-1 and KLRG1 receptors, whereas cytokine production is downregulated. In contrast, senescent NK cells show an increased secretion of pro-inflammatory cytokines (see below). An interesting difference between the exhaustion and senescence of NK cells is the observation that the exhausted state of NK cells can be reversed by receptor blockade therapy, but the senescence state is more stable. Currently, the signaling mechanisms controlling the senescence and exhaustion of both $\mathrm{T}$ and NK cells are under scrutiny because of their important role in chronic inflammatory diseases. 


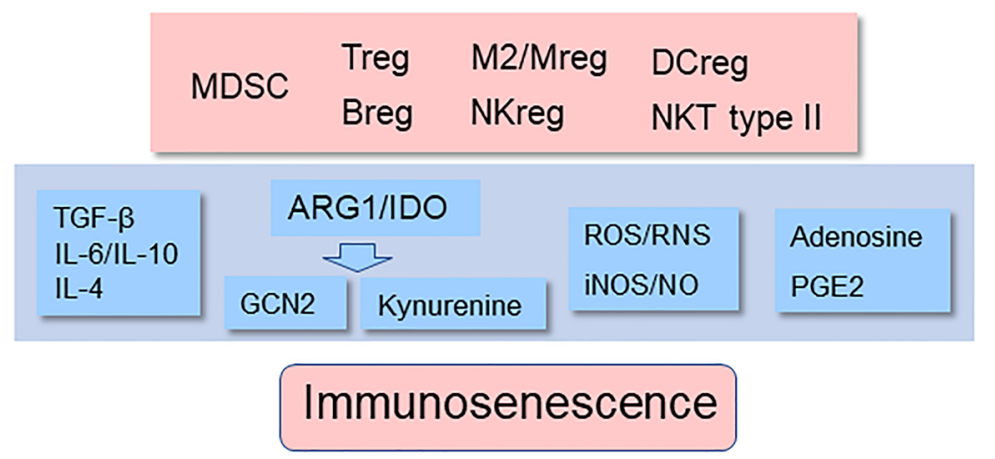

\begin{tabular}{|c|c|c|}
\hline T cells & B cells & NK cell \\
\hline $\begin{array}{l}\text { Reduced } \\
\text { - number of naive T cells } \\
\text { - TCR repertoire and } \\
\text { signaling } \\
\text { - cytotoxicity of CD8 T } \\
\text { cells } \\
\text { - responsiveness of T } \\
\text { cells }\end{array}$ & $\begin{array}{l}\text { Reduced } \\
\text { - B cell lymphopoiesis } \\
\text { - number of naive B cells } \\
\text { - B cell repertoire } \\
\text { - response to new antigens } \\
\text { - production of antibodies } \\
\text { Increased }\end{array}$ & $\begin{array}{l}\text { Reduced } \\
\text { - surveillance capacity } \\
\text { - cytotoxic activity } \\
\text { - cytokine production } \\
\text { - chemokine production } \\
\text { - responsiveness to cytokines } \\
\text { Alterations in NK cell subsets }\end{array}$ \\
\hline $\begin{array}{l}\text { Increased number of } \\
\text { memory } T \text { cells }\end{array}$ & $\begin{array}{l}\text { production of autoreactive } \\
\text { antibodies }\end{array}$ & Enhanced SASP \\
\hline Imbalance of Th subsets & - number of memory B cells & \\
\hline nhanced SASP & - number of immature $B$ cells & \\
\hline
\end{tabular}

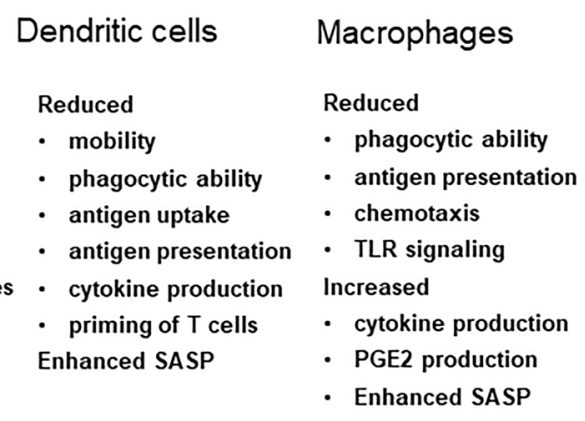

GCN2, general control nonderepressible 2; IL, interleukin; iNOS, inducible nitric oxide synthase; M2/Mreg, M2 macrophage (regulatory macrophage); MDSC, myeloid-derived suppressor cells; NKreg, regulatory natural killer cells; NKT type II, type II natural killer T cells; PGE2, prostaglandin E2; RNS, reactive nitrogen species; ROS, reactive oxygen species; SASP, senescence-associated secretory phenotype; TCR, T cell receptor; TGF- $\beta$, transforming growth factor- $\beta$; TLR, Toll-like receptor; Treg, regulatory $\mathrm{T}$ cells

production of lymphopoietic progenitors is downregulated with aging [27]. Moreover, the responsiveness of $\mathrm{T}$ cells to certain cytokines declines with aging as does the cytotoxic activity of $\mathrm{CD}^{+} \mathrm{T}$ cells (Fig. 2). There is convincing evidence that immunosenescence is associated with disturbances in the function of the T cell receptor (TCR) and its co-receptors, especially that of the stimulatory CD28 receptor. Particularly, a loss of CD28 receptors is a hallmark of senescent $T$ cells [25]. The clear decrease in the diversity of the human TCR repertoire with aging in both naïve $\mathrm{CD} 4^{+}$and $\mathrm{CD} 8^{+} \mathrm{T}$ cell populations impairs the recognition of antigens and reduces the activation of $\mathrm{T}$ cells [28]. In addition to $\mathrm{T}$ cells, the number of $\mathrm{B}$ cells also declines with aging (Fig. 2). Kennedy and Knight [29] revealed that MDSCs inhibited the generation of B cells in mouse BM cultures through the secretion of soluble factors. The soluble factors could be anti-inflammatory cytokines since TGF- $\beta$ is a potent inhibitor of B cell proliferation [30]. There are also age-related changes in the circulating $B$ cell subsets, i.e., the number of human naïve $B$ cells and the antigen-experienced memory $\left(\mathrm{CD} 27^{+}\right) \mathrm{B}$ cells are reduced 
with aging, whereas the presence of the exhausted memory $\left(\mathrm{CD} 27^{-}\right) \mathrm{B}$ cells increases [31]. Aging also affects the B cell repertoire and antibody production, e.g., the production of autoreactive antibodies is augmented with aging (Fig. 2). Frasca et al. [31] have reviewed in detail the changes present in the phenotypes and functions of senescent B cells in mice and humans.

NK cells are important cytotoxic cells which undertake immune surveillance and clearance of stressed cells in cooperation with cytotoxic $\mathrm{CD} 8^{+} \mathrm{T}$ cells. Considering the aging process, it does appear that senescent cells can be recognized and removed by NK cells [32]. It seems that the accumulation of senescent cells with aging is attributable to defects in the surveillance potential of NK cells [33]. There is substantial evidence that aging affects the diversity of NK cell subsets and thus the functional properties of mouse and human NK cells [14, 34]. The common alterations in the profiles of surface receptors appearing in NK cells with aging have been compiled in several reviews $[14,34,35]$. In brief, the number of CD56 ${ }^{\text {bright }} \mathrm{NK}$ cells declines in circulation with aging as well as the production of cytokines and chemokine. Moreover, the percentage of CD56 ${ }^{\mathrm{dim}} \mathrm{CD} 57^{\mathrm{pos}} \mathrm{NK}$ cells increases with aging, whereas that of $\mathrm{CD} 56^{\mathrm{dim}} \mathrm{CD} 57^{\text {neg }}$ cells is clearly downregulated. Interestingly, the $\mathrm{CD} 57^{\text {pos }}$ phenotype is a marker for the senescence state in human $\mathrm{CD} 8^{+} \mathrm{T}$ cells, whereas in NK cells, it represents terminal differentiation [36]. The frequencies of CD57 ${ }^{\text {pos }}$ cells are increased in the blood and tissues in chronic inflammatory conditions, such as chronic infections and cancers. Almeida-Oliveira et al. [35] demonstrated that the percentages of human natural cytotoxicity triggering receptors 1 (NCR1 or NKp46) and 3 (NCR3 or NKp30) in both CD56 $6^{\text {brigh }}$ and CD56 ${ }^{\text {dim }} \mathrm{NK}$ subsets were significantly reduced in elderly people. Moreover, Hazeldine et al. [37] reported that the release of perforin from human NK cells and its binding to target cells at the immunological synapse were clearly reduced with aging, thus decreasing the cytolytic activity of NK cells. These age-related alterations might explain the lower cytotoxicity of NK cells in aged individuals. Rajagopalan and Long [38] demonstrated that the sustained activation of KIR2DL4 (CD158d) receptor induced the senescence phenotype of human NK cells. They also reported that TRAF6/TAK1 signaling was able to activate the endosomal KIR2DL4 receptor and thus provoked the senescence of human NK cells. The TRAF/TAK1 signaling axis has several connections to TGF- $\beta$ and NF- $\kappa B$ signaling. Hazeldine and Lord [34] have examined in detail many alterations in NK cells associated with the aging process.

The age-related changes in the myeloid cells, such as monocytes, neutrophils, macrophages, and dendritic cells, representing innate immunity are far less consistent than those of T, B, and NK cells. Their properties are more dependent on changes in the tissue microenvironment, e.g., the phase and intensity of inflammation and the presence of immunosuppressive cells. Since the major function of dendritic cells (DC) is antigen presentation to T and B cells, they are able to control the efficiency of adaptive immunity. Furthermore, macrophages possess a wide contextdependent plasticity, e.g., the M1/M2 polarization is not only dependent on the inflammatory state, but changes in the extracellular matrix can also affect their activity [39]. The number of DCs seems to be stable in tissues with aging, although the amount of Langerhans cells decreases with aging in human skin [40]. However, certain key functions of DCs are impaired with aging, e.g., mobility and antigen uptake are decreased, and also antigen processing and presentation to T cells are downregulated [41, 42] (Fig. 2). The priming of $\mathrm{T}$ cells might also be impaired, since there exists a significant decline in the secretion of cytokines induced by the activation of Toll-like receptors (TLR) in human myeloid and plasmacytoid DCs [43]. There is clear evidence that the macrophages from aged humans display many functional deficiencies [44, 45]. For instance, phagocytic capacity and the activity of antigen presentation are significantly reduced in senescent macrophages. Their responses to inflammatory insults, e.g., to LPS exposure and infections, are considerably downregulated, impairing the resolution of inflammatory state. However, it is known that the age-related effects on macrophages are dependent on the type of insult and the tissue location of the macrophages [46].

\section{Similar characteristics of senescence in immune and non-immune cells}

The common hallmarks of cellular senescence are very well characterized in non-immune cells, whereas the cellular properties of senescent immune cells have been infrequently reported. Surprisingly, it has been demonstrated that there are major similarities in the common phenotypes between senescent immune and non-immune cells [6, 47, 48] (Table 1). The arrest of cell proliferation caused by an increase in the expression of cell cycle inhibitors, such as p16INK4a, p21WAF1, and p53, is a typical alteration encountered both in senescent immune and non-immune cells of mice and humans. For instance, these changes are present in senescent $\mathrm{T}$ cells [49-51], B cells [31], NK cells [52], and macrophages [53-55]. Cell cycle arrest is commonly associated with the increased expression of senescenceassociated $\beta$-galactosidase (SA- $\beta$-gal) and heterochromatin foci (SAHF) $[52-54,56,57]$ as well as the shortening of telomeres [58-60]. In particular, telomere shortening occurs in the replicative senescence of T cells. All these age-related changes are also common biomarkers of cellular senescence in non-immune cells of mice and humans [6] (Table 1). 
Table 1 Comparison of common characteristics shared by cellular senescence and immunosenescence

\begin{tabular}{|c|c|c|c|c|}
\hline Parameter & Cellular senescence & Immunosenescence & Immune cell type & Reference \\
\hline SA- $\beta-\mathrm{Gal}$ & Up & Up & $\mathrm{T}, \mathrm{NK}, \mathrm{M}$ & {$[52-54,56]$} \\
\hline SAHF & Up & Up & $\mathrm{T}, \mathrm{NK}$ & {$[52,57]$} \\
\hline Telomere shortening & Up & Up & $\mathrm{T}, \mathrm{B}, \mathrm{NK}, \mathrm{M}$ & [58-60] \\
\hline p16/INK4a & Up & Up & $\mathrm{T}, \mathrm{B}, \mathrm{M}$ & {$[49,53,54]$} \\
\hline p21/WAF1[ & Up & Up & $\mathrm{T}, \mathrm{NK}, \mathrm{M}$ & {$[50,52,55]$} \\
\hline p53 & Up & Up & $\mathrm{T}, \mathrm{M}$ & {$[51,55]$} \\
\hline Autophagy & Impaired & Impaired & $\mathrm{T}, \mathrm{M}$ & {$[56,61-63]$} \\
\hline Mitochondrial disturbances & Increased & Increased & $\mathrm{T}, \mathrm{B}$ & {$[60,63,66]$} \\
\hline Oxidative stress & Increased & Increased & $\mathrm{T}, \mathrm{B}, \mathrm{M}$ & {$[59,66-68]$} \\
\hline ER stress & Increased & Increased & $\mathrm{T}, \mathrm{M}$ & {$[64,65]$} \\
\hline SASP & Enhanced & Enhanced & $\mathrm{T}, \mathrm{B}, \mathrm{M}$ & {$[55,68,70,71]$} \\
\hline Apoptosis & Resistant & Resistant? & $\mathrm{T}, \mathrm{B}$ & {$[75-77]$} \\
\hline
\end{tabular}

Immune cells: $T$ T cells, $B$ B cells, $N K$ natural killer cells, $M$ macrophages

Diverse cellular stresses are associated with cellular senescence, both in immune and non-immune cells. There are significant alterations in the functions of autophagy, endoplasmic reticulum (ER), and mitochondria leading to cellular senescence displaying oxidative stress and disturbances in energy metabolism and protein homeostasis, although senescent cells remain metabolically active. There is robust evidence that the functions of autophagy [56, 61-63], ER [64, 65], and mitochondria [60, 63, 66] are disturbed in senescent mouse and human immune cells (Table 1). Currently, it is not known which of these three organelles is driving the senescence process, in either nonimmune or immune cells. Several studies have revealed that autophagic degradation is reduced in senescent $\mathrm{CD} 4^{+} \mathrm{T}$ cells and macrophages which impair the clearance of mitochondria and other organelles, thus provoking disturbances in their function [61, 63]. Bektas et al. [63] demonstrated that an age-related decline in autophagic degradation in human $\mathrm{CD}^{+} \mathrm{T}$ cells induced the accumulation of autophagosomes and increased the number of non-functional mitochondria. Stranks et al. [61] reported that the knockout of the mouse Atg 7 gene, an essential autophagy gene, induced several typical properties occurring in immunosenescent macrophages. For instance, impaired autophagy in mouse macrophages reduced mitochondrial respiration and increased glycolysis, whereas it increased the secretion of inflammatory factors. Hurst et al. [64] reported that an increased ER stress induced mitochondrial exhaustion in mouse and human T cells. Interestingly, they reported that an increase in the generation of mitochondrial ROS compounds provoked a mitochondrial collapse in T cells. An increased production of mitochondrial ROS can also trigger telomere attrition in aged human $\mathrm{CD} 8^{+}$ $\mathrm{T}$ cells [60]. Vida et al. [67] demonstrated that oxidative stress increased with aging in conjunction with a decrease of antioxidant defence in murine peritoneal leukocytes and especially in macrophages. The increases in the levels of ROS compounds and oxidized glutathione (GSSG) with an accumulation of lipofuscin impaired the functioning of senescent mouse macrophages. Interestingly, they observed that the macrophages from the long-lived mice preserved better their redox state and immune functions indicating that immunosenescence might enhance the oxi-inflamm-aging process. Accordingly, Garrido et al. [68] revealed that peritoneal macrophages and leukocytes sampled from the mice of two models of premature aging displayed decreased antioxidant levels accompanied by an increased quantity of oxidants and pro-inflammatory cytokines. Recently, Martinez de Toda et al. [69] screened a wide array of mouse immune cell parameters to determine which of them could be used as markers for the rate of the aging process. They reported that specific parameters were determinants of longevity in the adult age, e.g., lymphocyte chemotaxis and proliferation capacities as well as macrophage chemotaxis and phagocytosis activity. Furthermore, some other parameters predicted extreme longevity in very old age, such as the activity of NK cells and the levels of IL- 6 and IL- $1 \beta$ cytokines. These results indicate that certain functional activities and inflammatory parameters of immune cells can be utilized as the prognostic tools for the prediction of human lifespan.

There are several studies indicating that the phenotype of senescent immune cells displays the characteristics of the senescence-associated secretory phenotype (SASP), a typical pro-inflammatory phenotype of senescent non-immune cells. The SASP response has been detected in T cells $[25,68,70]$, B cells [71], and macrophages [55]. The pro-inflammatory SASP components include colony-stimulating factors (CSF), interleukins such as IL-6, IL-1 $\beta$, IL-8, and IL-10, and several chemokines. It seems that the pro-inflammatory SASP 
properties of immune cells, especially those of macrophages, have a key role in the maintenance of low-grade chronic inflammaging condition in tissues. NF- $\mathrm{KB}$ signaling is the major inducer of the SASP state both in senescent immune and non-immune cells [55, 72]. The NF-kB system also is a potent regulator of apoptotic cell death, either inhibiting or enhancing apoptosis [73]. Cellular senescence of non-immune cells has been associated with extensive resistance to apoptotic cell death [74] (Table 1). Considering immunosenescence, the situation seems to be more complex, and apoptosis is probably a context-dependent process, i.e., immunosenescence either increases resistance to apoptosis or enhances apoptotic cell death. For instance, Spaulding et al. [75] demonstrated that the antigen-induced replicative senescence of human $\mathrm{CD} 8^{+} \mathrm{T}$ cells displayed a robust resistance to apoptosis. In contrast, Dennett et al. [76] reported that the age-related decline in the expression of $\mathrm{CD} 25$ and $\mathrm{CD} 28$ receptors in human $\mathrm{T}$ cells increased their susceptibility to the Fas (CD95)-mediated apoptosis. Chong et al. [77] reported that the number of apoptosis resistant $\mathrm{CD} 27^{-} \mathrm{B}$ cells was increased in aged humans. Currently, virtually nothing is known about the role of other regulated cell death processes, e.g., pyroptosis and immunogenic cell death, in the decline of immune system with aging.

\section{Immunosenescence is associated not only with aging but also with chronic inflammatory conditions}

There is a debate whether immunosenescence is a cause or a consequence of a low-grade inflammation with aging [17]. It seems very plausible that immunosenescence is a consequence of inflammaging, since diverse inflammatory conditions, unrelated to the aging process, display extensive immunosenescent state of immune cells, e.g., many infections and autoimmune diseases [4, 26, 78]. For instance, rheumatoid arthritis induces premature $\mathrm{T}$ cell senescence displaying a deficiency of CD28 receptor and enhanced proinflammatory SASP properties [78, 79]. Immunosenescence is clearly increased in several age-related diseases, e.g., cardiovascular and neurodegenerative diseases $[15,16]$. In fact, it seems probable that it is chronic inflammation rather than the aging process which augments immunosenescence. Cytomegalovirus infection can also enhance immunosenescence with aging. Recently, it has been reported that the infection by SARS-CoV2 virus induced an extensive immunosenescence response in older patients [80] which might be explained by the enhanced SASP activity of immune cells in aged individuals (see above). There is also convincing evidence that obesity accelerates immunosenescence in murine adipose tissues [81]. Evidently, it is related to chronic inflammation in adipose tissues rather than simply to the aging process. Moreover, neuropsychiatric disorders, e.g., major depression and bipolar disorder, are associated with chronic inflammation and immunosenescence $[82,83]$.

Immunosenescence has also been associated with tumorigenesis [5] and transplantation [84]. There is a debate whether immunosenescence in tumor sites might be attributed either to an age-related immune deficiency or to the chronic inflammatory microenvironment. Interestingly, in tumors, there is also an accumulation of senescent nonimmune cells which are able to suppress tumor growth, but on the other hand, they can also enhance tumorigenesis through the proinflammatory SASP response [85]. When considering immunosenescence, $\mathrm{T}$ cells display the characteristics of senescence and exhaustion in the tumor microenvironment [19]. Moreover, Sanchez-Correa et al. [86] reported that human NK cells possessed features of immunosenescence in acute myeloid leukemia impairing immunosurveillance. It is known that the number of immunosuppressive regulatory cells, e.g., MDSCs, Tregs, and tumor-associated macrophages (TAM) robustly increases in tumor sites [87]. Given that regulatory immune cells are potent suppressors of the effector subsets of immune cells, this indicates that the activation of immunosuppressive network most probably induces immunosenescence in the tumor microenvironment. In addition, several studies have revealed that immunosuppressive cells, such as MDSCs, Bregs, regulatory macrophages (M2 subsets), and tolerogenic dendritic cells control transplantation tolerance in mice and humans [88]. This tolerance is most probably associated with the immunosenescence induced by the accumulation of immunosuppressive cells around the transplants. Recently, Sacchi et al. [89] reported that inflammation induced the expansion of a polymorphonuclear MDSC population in the blood of COVID-19 patients. They also demonstrated that MDSCs suppressed the specific responses of $\mathrm{T}$ cells to the SARSCoV-2 virus-induced infection, e.g., inhibiting the release of IFN- $\gamma$ cytokines. We have recently described that the age-related senescence of immune cells shows very similar phenotypes as those induced by immunosuppressive MDSCs [24]. As a whole, it seems that immunosenescence is caused by immunosuppressive cells as a reaction to the chronic inflammatory state (see below).

\section{Activation of immunosuppressive network promotes immunosenescence}

\section{Immunosuppressive network}

The immune system possesses extensive plasticity to respond and adapt to both systemic and local microenvironmental insults. There is convincing evidence that acute inflammatory responses evoke compensatory anti-inflammatory/ 
immunosuppressive responses to induce a resolution phase both at the systemic level and in tissue microenvironments. Autoimmune diseases, pathogen-induced sepsis, and traumatic injuries are known to induce a systemic inflammatory response syndrome (SIRS) which is opposed by a compensatory anti-inflammatory syndrome (CARS) [7, 90]. In addition, chronic inflammatory states within tissues also provoke many immunosuppressive responses intended to counteract the harmful effects of persistent inflammation $[8,9]$. The persistent presence of an immunosuppressive state can be detrimental, for instance, the chronic inflammation existing in tumor microenvironments provokes immunosuppression which allows tumor cells to escape immune surveillance [87]. The immunosuppressive network involves the regulatory Tregs, Bregs, NKregs, and DCregs, as well as M2 subsets of macrophages (Mregs) and type II NKT cells. The immature MDSCs, both monocytic and polymorphonuclear subpopulations (M-MDSC/PMN-MDSC), are also included in the immunosuppressive network [9, 91, 92] (Fig. 2). The close cooperation between the members of this immunosuppressive network is a characteristic property in the function of the network. For instance, the network's members can potentiate each other's immune suppressive activities and even enhance the differentiation of immunosuppressive cells $[9,91,93]$. The cells of host tissues are also able to educate immune cells to adopt immunosuppressive phenotypes [94]. Changes in the components of the extracellular matrix can also control the properties of immune cells in inflammatory sites [95]. These observations indicate that the plasticity of mouse and human immune cells allows the immune system to counteract inflammatory insults and thus maintain tissue homeostasis.

The cells of the immunosuppressive network possess powerful tools to suppress the functions of immune cells. The armament inhibits the functions of effector cells through (i) the secretion of anti-inflammatory cytokines, such as TGF- $\beta$, IL-4, IL-10, and IL-18, (ii) the release of reactive oxygen and nitrogen species (ROS/RNS), (iii) the generation of adenosine and prostaglandin E2 (PGE2) which are immunosuppressive factors, and (iv) increases in the expression and secretion of amino acid-catabolizing enzymes, i.e., arginase 1 (ARG1) and indoleamine 2,3-dioxygenase (IDO) [30, 96-98] (Fig. 2). Anti-inflammatory cytokines not only are immune mediators between immunosuppressive cells, but they also suppress the functions of pro-inflammatory immune cells and induce their immunosenescence. For instance, TGF- $\beta$ exposure upregulates the expression of the cyclin-dependent kinase inhibitors thus arresting the proliferation of $\mathrm{T}$ cells as well as it inhibits the activation of $\mathrm{T}$ cells, disturbs the differentiation of Th cells, and inhibits the cytotoxicity of CD8 T cells [30]. TGF- $\beta$ signaling also reduces the proliferation of $\mathrm{B}$ cells, inhibits antibody production, and induces apoptosis of immature and resting $\mathrm{B}$ cells. In human NK cells, TGF- $\beta$ suppresses their cytolytic activity and the production of cytokines [30, 99]. Moreover, TGF- $\beta$ exposure reduces the phagocytic activity and antigen presentation of macrophages [30]. All these phenotypes are reminiscent of those present in immunosenescent phenotypes of immune cells (Fig. 2). It is known that TGF- $\beta$ can also arrest the cell cycle and induce cellular senescence of non-immune cells [100]. ROS/RNS compounds secreted by immunosuppressive cells inhibit the TCR signaling of mouse $\mathrm{T}$ cells as well as suppressing the cytotoxic activity, cytokine production, and signal transduction of rat NK cells [101, 102]. ROS/RNS compounds are also known to induce cellular senescence of non-immune cells [103]. Moreover, immunosuppressive cells, e.g., inducible Tregs, generate adenosine and prostaglandin E2 (PGE2) which are potent suppressors of effector T cells and NK cells [97, 104] (Fig. 2). Adenosine and PGE2 inhibit the functions of T cells and NK cells by stimulating cyclic AMP signaling. The robust increase in the production of PGE2 is associated with many human age-related inflammatory diseases, such as atherosclerosis [105].

The age-related decline in the function of immune system was discovered over 40 years ago [106-108]. Interestingly, these early studies indicated that immunosenescence was induced by the increased activity of immune suppressor cells [107, 108]. In their seminal study, Roder et al. [107] demonstrated that mouse spleen and bone marrow contained immune cells which were able to suppress the immune responses induced by anti-sheep erythrocytes (antiSRBC). Interestingly, they revealed that the immunosuppressive response was robustly increased with aging and preceded or paralleled the age-related immunosenescence. The immunosenescence was mediated through the soluble factors from suppressor cells. In addition, Singhal et al. [108] reported that mouse spleen and bone marrow contained suppressive B-type cells which were able to inhibit the activation and differentiation of $\mathrm{T}$ and $\mathrm{B}$ lymphocytes through their secreted mediators. The activity of suppressor B cells was significantly increased with aging, and the cells were able to induce the age-related immunosenescence. After these ground-breaking observations, it took 30 years before many studies revealed that there was a significant age-related increase in the number of Tregs in the circulation of both humans $[109,110]$ and mice [111]. Accordingly, the number of MDSCs increased with aging in the blood of humans [112] and mice [113]. Currently, there are only a few studies which have focused on the alterations occurring in immunosuppressive cells within tissues during the aging process. For instance, with aging, there was an increased presence of immunosuppressive M2 macrophages in the mouse bone marrow, spleen, lungs, and skeletal muscles $[114,115]$. Accordingly, it is known that the level of Tregs was upregulated with aging in mouse skin [116] and adipose 
tissues [117]. Ruhland et al. [118] demonstrated that the skin of elderly humans contained not only an increased number of senescent, INK4a-positive cells but that there was also a robust upregulation of immunosuppressive MDSCs. They also revealed that the experimentally induced senescence of stromal cells in the mouse skin provoked local inflammation and subsequently enhanced the expansion of MDSCs and Tregs. These studies clearly indicate that chronic inflammation can induce a counteracting activation of immunosuppressive network within tissues.

\section{Immature MDSCs are enhancers of immunosenescence}

MDSCs are a heterogeneous population of immature myeloid cells which originate from the common myeloid progenitor cells in the bone marrow [10]. Many pathological processes disturb myelopoiesis, increasing the generation of immature myeloid cells (IMC) which can become differentiated into MDSCs. Inflammatory mediators, such as colony stimulating factors (CSF) and many chemokines, impair the maturation of MDSCs into macrophages, granulocytes, or dendritic cells. There is significant plasticity in the production of MDSCs and subsequently in their differentiation into the other myeloid cells [10, 119]. Basically, there are two types of MDSCs, i.e., M-MDSC and PMNMDSC populations, which possess impressive immunosuppressive properties against different sets of immune cells. For instance, MDSCs are the potent inhibitors of the proliferation of T cells; this effect is mediated through the secretion of IL-6, IL10, and TGF- $\beta$ cytokines as well as ROS and RNS compounds [120]. Nagaraj et al. [102] revealed that mouse MDSCs robustly released ROS compounds and nitric oxide (NO) forming peroxynitrite which nitrated the tyrosine residues of the TCR receptor. This process impaired the recognition of antigens, inhibited the signaling by TCRs inducing $\mathrm{T}$ cell tolerance which is a typical characteristic of immunosenescent T cells (Fig. 2). Kennedy and Knight [29] reported that mouse MDSCs inhibited the lymphopoiesis of $\mathrm{B}$ cells in bone marrow cultures. MDSCs also reduced the proliferation, homing, and antibody production of mature human B cells [121]. The suppression of B cells was mediated through the secretion of TGF- $\beta$, IL-10, and PGE2 by MDSCs. In contrast, MDSCs stimulated the expansion and activity of immunosuppressive Tregs [122] and Bregs [123]. This indicates that MDSCs have opposite effects on T and B cell populations in inflammatory conditions; they can either augment the immunosuppressive properties of Tregs and Bregs or suppress the immune activities of effector $\mathrm{T}$ and $\mathrm{B}$ cells evoking immunosenescent phenotypes.

It is known that MDSCs can also induce clear changes in the phenotypes of DCs, NK cells, and macrophages which resemble those present in the immunosenescent state [24]
(Fig. 2). For instance, Poschke et al. [124] demonstrated that human M-MDSCs impaired the maturation of DCs, disturbed their ability to take up antigens, and inhibited the IFN $\gamma$ production by human T cells. Hu et al. [125] also observed that mouse MDSCs actively secreted IL-10 cytokines which downregulated IL-12 production from DCs, thus suppressing their capacity to stimulate the functions of T cells. MDSCs are also potent suppressors of the cytotoxic functions of NK cells. For instance, Hoecht et al. [126] reported that the M-MDSCs, isolated from human hepatocellular carcinoma, suppressed the cytotoxicity of autologous NK cells and inhibited the secretion of cytokines. The suppression of NK cells disturbed the defense not only against tumors but also against viral infections [127]. Moreover, MDSCs are potent inhibitors of the immune surveillance performed by NK and CD8 T cells (see below). In inflammatory conditions, there exists a close interaction between MDSCs and tissue macrophages [128]. For instance, Nguyen et al. [129] demonstrated that during an infection in the mouse peritoneum, IL-10 induced the differentiation of blood monocytes into the $\mathrm{MHCII}^{\mathrm{low}}$ macrophages possessing an elevated capacity to phagocytose apoptotic cells, whereas they were unable to present antigens to T cells. Given the abundant plasticity of tissue macrophages, Stout and Suttles [39] suggested that the immunosenescence of macrophages would be controlled by the changes in the extracellular matrix and immune cells present in aged tissues.

\section{Tregs induce T cell senescence}

As discussed above, there is an opposite effect in the subtypes of $\mathrm{T}$ cells with aging, i.e., the number of naïve $\mathrm{T}$ cells declines extensively, whereas that of Tregs increases. There are several studies indicating that the members of the immunosuppressive network can convert $\mathrm{T}$ cells into immunosuppressive Tregs [91, 122]. The conversion of naïve and efferent $\mathrm{T}$ cells into the regulatory phenotype of $\mathrm{T}$ cells (Tregs) can be evoked by IL-10 and TGF- $\beta$ cytokines which increase the expression of FoxP3, a master gene of Tregs. Conversely, Tregs are able to induce the senescent phenotype of $\mathrm{T}$ cells $[12,13]$. For instance, Ye et al. [12] demonstrated that human Treg cells induced the senescent phenotype of both naïve and effector $T$ cells. The senescent state was induced through the p38 and ERK1/2 signaling pathways which increased the expression of $\mathrm{p} 16, \mathrm{p} 21$, and $\mathrm{p} 53$, i.e., the cellcycle inhibitors which are common markers of senescent cells. Senescent T cells displayed a strong downregulation in the expression of costimulatory CD27 and CD28 proteins, whereas the secretion of pro-inflammatory factors, such as IL- 6 and TNF- $\alpha$, was enhanced indicating the presence of the SASP state. Surprisingly, senescent T cells showed an upregulation in the secretion of anti-inflammatory IL-10 and TGF- $\beta$ cytokines which implies that senescent $\mathrm{T}$ cells 
are able to expand immunosenescence within tissues. Subsequently, Liu et al. [13] reported that human senescent T cells did not display the phenotype of exhausted $\mathrm{T}$ cells, and moreover, senescent $\mathrm{T}$ cells were different from the anergic T cells. They also revealed that the STAT1 and STAT3 signaling pathways were involved in the senescence process of $\mathrm{T}$ cells. In addition to the $\mathrm{CD} 4{ }^{+} \mathrm{CD} 25^{+}$Tregs, also human $\gamma \delta$ Tregs were able to suppress the functions of naïve and effector T cells [130]. It seems that Tregs enhance not only the immunosenescence of $\mathrm{T}$ cells but also that of NK cells $[131,132]$.

\section{Immunosuppression prevents the immune surveillance by $\mathrm{NK}_{\text {and }} \mathrm{CDB}^{+} \mathrm{T}$ cells}

$\mathrm{NK}$ and $\mathrm{CD} 8^{+} \mathrm{T}$ cells are the major immune cells which perform immune surveillance within tissues and eliminate dysfunctional and injured cells. It is known that cytotoxic $\mathrm{NK}$ and $\mathrm{CD} 8^{+} \mathrm{T}$ cells recognize senescent cells and induce their death and clearance from tissues [32, 133]. However, the immunosenescence of $\mathrm{NK}$ and $\mathrm{CD} 8^{+} \mathrm{T}$ cells impairs the surveillance process and thus allowing the accumulation of senescent cells, both immune and non-immune cells, within tissues during the aging process [33]. There is substantial evidence that immunosuppressive cells, especially M-MDSCs and Tregs, inhibit the immunosurveillance capacity and cytotoxic activity of $\mathrm{NK}$ and $\mathrm{CD} 8^{+} \mathrm{T}$ cells $[126,131,132]$. To suppress the cytotoxicity of NK and $\mathrm{CD} 8^{+} \mathrm{T}$ cells, MDSCs and Tregs release soluble factors, such as NO, adenosine, and IDO. They can also form the contact-dependent interaction with NK cells through the membrane-bound TGF- $\beta$ and the activating NKp30 receptors [126, 132, 134]. For instance, Li et al. [134] demonstrated that mouse MDSCs inhibited the expression of NKG2D receptors and the cytotoxic activity of NK cells through their membrane-bound TGF- $\beta 1$ proteins. It seems that MDSCs inhibit the function of NK cells through the blocking of NKp30 (NCR3) and NKG2D receptors, two killer receptors present in NK cells. Tregs also inhibit the function of NK cells via the TGF- $\beta / \mathrm{NKG} 2 \mathrm{D}$ complex [132]. Thus, it seems that the MDSC/Treg-induced immunosenescence of NK cells impairs the clearance of senescent cells, tumor cells, and many pathogens with aging as well as in inflammatory conditions.

\section{Signaling mechanisms involved in immunosuppression-induced immunosenescence}

When examining the characteristics of the senescent state of non-immune (called here cellular senescence) and immune (immunosenescence) cells (Table 1), it seems that similar mechanisms exist in the regulation of senescence, although there might be some immune-specific mechanisms. There is more research data from the mechanisms leading to cellular senescence than that available about immunosenescence. It is known that cellular senescence is commonly associated with extrinsic and intrinsic damages, whereas the plasticity of immune cells might affect the senescence of immune cells. The arrest of the cell-cycle is the major phenotype of both cellular senescence and immunosenescence which is attributed to the activation of cyclin-dependent kinase inhibitors (CDKI), e.g., p16, p21, and p53 (Table 1). There are multiple insults which can arrest the cell-cycle, such as DNA damage, amino acid deficiency, and many soluble factors. For instance, TGF- $\beta$ is a potent inhibitor of cellular proliferation and an inducer of cellular senescence [30, 100]. Delisle et al. [135] demonstrated that TGF- $\beta$ activated Smad 3 signaling in mouse $\mathrm{CD}^{+} \mathrm{T}$ cells and inhibited the responses mediated through the CD28-dependent signaling, e.g., the growth and proliferation of T cells. Accordingly, Tiemessen et al. [136] revealed that TGF- $\beta$ administration inhibited the cell cycle progression of human antigen-specific $\mathrm{CD} 4^{+} \mathrm{T}$ cells. Interestingly, TGF- $\beta$ did not affect the production of cytokines indicating that the regulation of cell cycle arrest and the proinflammatory SASP are separated. Viel et al. [137] reported that TGF- $\beta$ repressed the activity of mTOR in human NK cells, inhibiting their proliferation and reducing their cytotoxicity. It is known that $\mathrm{Smad} 3$ signaling stimulates the expression of CDKIs and subsequently prevents cell proliferation and induces cellular senescence [100].

There is convincing evidence that p38 mitogen-activated protein kinase (p38MAPK) has a crucial role in the generation of cellular senescence and immunosenescence [69, 138, 139]. A diverse set of insults associated with immunosuppression, e.g., TGF- $\beta$ and IL-10 as well as oxidative (ROS/RNS) and endoplasmic reticulum (ER) stresses, can activate p38MAPK signaling which in downstream activates several protein kinases, transcription factors, and other regulatory proteins. For instance, p38MAPK is an important Smad-independent target of TGF- $\beta$ signaling [140]. The activation of $\mathrm{p} 38 \mathrm{MAPK}$ has been linked to cell-cycle arrest, DNA damage, telomere shortening, SASP induction, and autophagy inhibition in senescent immune cells [69, 139, 141, 142], all of which are hallmarks of immunosenescence (Table 1). Interestingly, Ding et al. [143] reported that the post-traumatic (trauma/hemorrhage) immunosuppression impaired mouse lung immunity against pneumococcal pneumonia. They revealed that an increase in the activity of p38MAPK reduced the phagocytosis of lung macrophages and impaired the killing of Streptococcus pneumoniae in post-traumatic mice. The exposure with p38MAPK inhibitor prevented these immune disturbances and improved mouse survival. Accordingly, Lanna et al. [142] demonstrated that sestrins, p53-inducible stress-sensing proteins, were able to bind to ERK, JNK, and p38MAPK enzymes and to establish 
the formation of a sestrin-MAPK activation complex (sMAC) in mouse and human $\mathrm{T}$ cells. The expression of sestrins displayed a tenfold increase in $\mathrm{CD} 4^{+} \mathrm{T}$ cells of elderly subjects as compared to younger individuals. The formation of the sMAC complexes was also significantly increased in human $\mathrm{T}$ cells with aging. They reported that the activation of sMAC kinases promoted T cell senescence, but each of the MAPKs controlled unique properties of senescence, e.g., p38MAPK inhibited telomerase activity and evoked telomere shortening. In addition to telomerase inhibition, Lanna et al. [139] reported that the activation of p38MAPK also inhibited human T cell proliferation, induced DNA damages, and disturbed the function of the TCR signalosome.

The TGF- $\beta$ signaling pathways as well as the activation of p38MAPK are also important inducers of the SASP state which is associated with cellular senescence and immunosenescence $[69,72,144]$. Signaling through both TGF- $\beta$ and $\mathrm{p} 38 \mathrm{MAPK}$ can activate the nuclear factor- $\mathrm{\kappa B}(\mathrm{NF}-\mathrm{\kappa B})$ system which is the major inducer of the genes involved in the SASP secretome [72]. Freund et al. [144] reported that p38MAPK regulated the pro-inflammatory SASP secretome via the activation of NF- $\mathrm{\kappa B}$ signaling in human fibroblasts. Accordingly, Callender et al. [69] demonstrated that the activation of p38MAPK induced the SASP state in human senescent $\mathrm{CD} 8^{+} \mathrm{T}$ cells. Wang et al. [55] reported that LPS treatment for $24 \mathrm{~h}$ of mouse macrophages and human peripheral blood mononuclear cells (PBMC) evoked a senescent state through the NF- $\mathrm{KB}$-induced activation of bromodomain-containing protein 4 (BRD4), an epigenetic regulator of gene transactivation. Senescent macrophages displayed a clear SASP state, and moreover, they showed an increased lipid uptake, a process associated with atherosclerosis. The inhibition of BRD4 prevented the senescence of mouse macrophages and lipid accumulation into senescent macrophages. It does seem that immunosenescence is under epigenetic regulation (see below).

Amino acid catabolism is a potent immunosuppressive mechanism since many effector immune cells are auxotropic and thus are unable to synthesize several amino acids, e.g., L-arginine and tryptophan [145]. Immunosuppressive cells express and secrete ARG1 and IDO enzymes which diminish the amounts of L-arginine and tryptophan, respectively, from the inflammatory microenvironment. The shortage of amino acids stimulates the expression of general control nonderepressible 2 (GCN2), a stress-kinase which activates eIF2 $\alpha$ kinase and ATF4 transcription factor [146]. Subsequently, eIF2 $\alpha$ and ATF4 inhibit protein synthesis and the proliferation of immune cells in inflammatory sites. It is known that a deficiency of amino acids not only inhibits the proliferation of $\mathrm{T}$ cells, but it also interferes with their TCR and co-stimulatory mechanisms and consequently can induce the anergy of T cells [147]. IDO catabolizes tryptophan into kynurenine and a number of other active metabolites. The kynurenine pathway is a powerful immunoregulation mechanism, i.e., it inhibits the functions of $\mathrm{T}$ and NK cells, whereas it activates Tregs and MDSCs [148, 149]. For instance, the kynurenine pathway induced the exhaustion of human $\mathrm{CD}^{+} \mathrm{T}$ cells [150] and provoked the selective apoptosis of mouse Th1 cells [151]. Della Chiesa et al. [152] demonstrated that kynurenine exposure impaired the expression of the activating NKp30 and NKG2D receptors of human NK cells. NKp30 and NKG2D receptors are important immune surveillance receptors, and thus kynurenine inhibited the immune recognition and clearance process performed by NK cells.

Interestingly, Mezrich et al. [153] demonstrated that kynurenine activated the aryl hydrocarbon receptor (AhR) which induced the differentiation of mouse naive $T$ cells into the FoxP3-positive Tregs. They also reported that TGF- $\beta$ upregulated the expression of AhR in mouse T cells and thus enhanced their immunosuppressive activity. Subsequently, there has been intensive research activity to reveal the role of the IDO/kynurenine/AhR axis in pathological processes. For instance, it was claimed that kynurenine inhibited autophagy and promoted cellular senescence in mouse mesenchymal stem cells through the AhR pathway [154]. The aging process is associated with an increase in the expression of IDO and the enhanced production of kynurenine [155]. In particular, the kynurenine pathway is activated in chronic inflammatory conditions, such as atherosclerosis [156]. It is known that the kynurenine-mediated activation of $\mathrm{AhR}$ is a strong stimulating signal for the generation of Tregs in mice, whereas the blockade of the activity of AhR restricted the immunosuppression induced by kynurenine [157]. Moreover, Neamah et al. [158] demonstrated that the activation of AhR with the environmental toxin 2,3,7,8tetrachlorodibenzo-p-dioxin (TCDD) in mice induced a massive chemokine induction which promoted the mobilization of both M-MDSCs and PMN-MDSCs from the bone marrow to the peritoneal cavity. The TCDD-induced MDSCs robustly suppressed the activation of $\mathrm{T}$ cells and also reduced the inflammation after Con A-induced hepatitis. Although the expression of AhR is low in many subsets of lymphocytes, the activation of $A h R$ was able to suppress the differentiation of B cells and reduce their antibody production [159]. It seems that amino acid deprivation stimulates extensive immunosuppression through the activation of Tregs and MDSCs which subsequently suppress effector immune cells and provoke immunosenescence through the secretion of anti-inflammatory cytokines.

\section{Immunosuppressive factors are epigenetic masters of immunosenescent state}

There is substantial evidence that epigenetic mechanisms control the cell lineage commitments and subsequently cell-type specific differentiation and maturation processes 
[160]. However, the chromatin landscape of mature cells can be reprogrammed into different cellular phenotypes; especially, immune cells display a significant plasticity which is dependent on epigenetic remodelling [161]. There are several studies indicating that aging processes as well as the cellular senescence state are associated with robust changes in the chromatin landscape and transcription signature $[162,163]$. It is known that epigenetic mechanisms are involved in the generation of both chronic inflammatory and the SASP states [164, 165]. The senescence-associated epigenetic changes in the chromatin landscape include (i) increased formation of heterochromatin domains (SAHF), (ii) global DNA hypomethylation concurrently with focal hypermethylation, (iii) repressive histone modifications, (iv) altered nucleosomal compositions, and (v) perturbations of the contacts between nuclear lamina and chromatin structures [162]. For instance, Lyu et al. [166] reported that TGF- $\beta$ signaling via Smad factors enhanced the accumulation of miR-29a/c which suppressed the expression of Suv4$20 \mathrm{~h}$ histone methyltransferase thus reducing the methylation of genomic H4K20 sites in human fibroblasts. This loss of H4K20 methylation disturbed the DNA repair processes and promoted cellular senescence and accelerated cardiac aging in mice.

The mechanisms of epigenetic regulation of immunosenescence are still not as broadly understood as those of cellular senescence. However, the major signaling pathways inducing immunosenescence involve the TGF- $\beta /$ SMAD and the IL-10/STAT3 pathways which are known to control the activity of several important epigenetic regulators, e.g., DNA methyltransferases and histone demethylases [164, 167]. In addition, the expression of $T G F-\beta 1, I L-10, A h R$, and $I D O I$ genes are the subject of complex epigenetic regulation [168-171]. Epigenetic mechanisms also regulate the activity of the immunosuppressive network, e.g., by controlling the expression of FoxP3 gene, the master gene of Tregs [172]. In addition, TGF- $\beta$ exposure was reported to reduce the immune surveillance activity of mouse and human NK cells via epigenetic regulation [98]. By exploiting omics techniques, Zhao et al. [173] demonstrated that there are significant changes in the transcriptomes, miRNAomes, and DNA methylomes of human $\mathrm{CD} 4^{+} \mathrm{T}$ cells during the aging process. Their results indicated that the expression levels of many age- and immune-related genes were under the regulation of DNA methylation. Moreover, Sidler et al. [174] reported that the aging process evoked significant changes in epigenetic regulation and gene expression in rat thymus and spleen which could induce thymic involution and peripheral immunosenescence. The epigenetic hallmarks of $\mathrm{T}$ cell aging include a global decrease in DNA methylation, whereas there is an increase in the number of heterogeneous loci of methylated CpG [175]. These scattered DNA methylation sites have been assessed as an epigenetic clock which can be used to evaluate the difference between the epigenetic age and the chronological age [176]. Many inflammatory diseases associated with increased immunosenescence, such as HIV infections, accelerate the epigenetic clock [177].

\section{Future perspectives: to rejuvenate or to prevent immunosuppression?}

Currently, there is intense research activity attempting to understand whether it is possible to rejuvenate senescent cells or even cleanse them via senolysis from aged tissues. A plethora of mechanisms have been proposed as ways to inhibit age-related senescence and thus delay the aging process $[163,178,179]$. It seems that the prevention of those signaling pathways leading to the senescent state or the reprogramming of the epigenetic landscape might maintain the efficiency of the immune system with aging and pathological conditions. There are several experimental studies indicating that the blockage of the distinct signaling pathways associated with immunosenescence would be able to alleviate the immune deficiency, e.g., the inhibition of p38MAPK signaling [180], the inhibition of phosphoinositide 3-kinase activity [181], and the downregulation of inhibitory SHP-1 phosphatase [182]. Moreover, many experimental approaches have been exploited to attempt to rejuvenate immunosenescent $\mathrm{T}$ cells in elderly individuals, e.g., through the administration of certain interleukins, growth factors, checkpoint inhibitors, and diets as well as exposure to extracellular vesicles obtained from the serum of young donors [183, 184]. Moreover, Keren et al. [185] demonstrated that the depletion of $\mathrm{B}$ cells from old mice stimulated B cell lymphopoiesis in their bone marrow and rejuvenated the peripheral B cell lineage. More recently, some attempts have been made to turn epigenetic clocks backwards in immunosenescent cells [186]. For instance, the inhibition of the bromodomain protein BRD4 with JQ-1 and I-BET762 prevented the LPS-induced senescence of human THP-1 macrophages [55]. This treatment downregulated the expression of $\mathrm{p} 16, \mathrm{p} 21$, and $\mathrm{p} 53$, reduced the number of SA- $\beta$-gal-positive cells, and inhibited the secretion of SASP cytokines and chemokines. However, there are a number of challenges to be overcome, e.g., in the targeting and safety of these drugs before epidrugs can be used in epigenetic therapy.

Given that increased immunosuppression evokes immunosenescence, it seems pointless to rejuvenate immunosenescent cells with aging and in many inflammatory pathological conditions, since the enhanced immunosuppressive armament will prevent a permanent rejuvenation. The most reasonable therapeutic target would seem to be immunosuppressive cells, especially MDSCs and Tregs, which are able to support immunosuppression. It is known that immunosuppression is a major problem in cancer biology, thus 
different strategies have been exploited in attempts to inhibit the activities of MDSCs and Tregs as ways to improve the efficacy of immunotherapy [187, 188]. For instance, the immunosuppressive functions of MDSCs have been inhibited by (i) normalizing their production in myelopoiesis, (ii) promoting their maturation to effector immune cells, (iii) reducing their trafficking and expansion, (iv) inhibiting their immunosuppressive activities, and (v) depleting their presence in tumors. There are several pharmacological compounds which have been demonstrated to inhibit the immunosuppressive activity of MDSCs, e.g., many phytochemicals suppress the activity of MDSCs [189]. Interestingly, the agonists binding to TLR7 and TLR8, e.g., resiquimod, promote the differentiation of MDSCs into macrophages and dendritic cells [190]. Considering that Tregs maintain the immune tolerance of the body, their inhibition will demand more specific mechanisms in order to avoid the generation of autoimmune diseases. There are many approaches which could be employed to inhibit the functions of Tregs, e.g., (i) targeting their immune checkpoint receptors, (ii) skewing them towards anti-tumor $\mathrm{T}$ cell phenotypes, (iii) targeting specific Treg proteins, such as FoxP3, and (iv) inhibiting their metabolism [188]. Moreover, given that immunosuppressive cells generate adenosine, there are studies indicating that the inhibition of the adenosinergic pathway was able to rejuvenate innate and adaptive immunity in tumors [191]. Many anti-aging compounds, e.g., metformin, have been shown to inhibit the functions of MDSCs and Tregs [192, 193]. Currently, it is not known whether these compounds will be able to prevent immunosenescence by inhibiting the immunosuppressive network.

Acknowledgements The author thanks Dr. Ewen MacDonald for checking the language of the manuscript.

Author contribution This article is the sole work of the author.

Funding Open access funding provided by University of Eastern Finland (UEF) including Kuopio University Hospital.

\section{Declarations}

Conflict of interest The author declares no competing interests.

Open Access This article is licensed under a Creative Commons Attribution 4.0 International License, which permits use, sharing, adaptation, distribution and reproduction in any medium or format, as long as you give appropriate credit to the original author(s) and the source, provide a link to the Creative Commons licence, and indicate if changes were made. The images or other third party material in this article are included in the article's Creative Commons licence, unless indicated otherwise in a credit line to the material. If material is not included in the article's Creative Commons licence and your intended use is not permitted by statutory regulation or exceeds the permitted use, you will need to obtain permission directly from the copyright holder. To view a copy of this licence, visit http://creativecommons.org/licenses/by/4.0/.

\section{References}

1. Franceschi C, Valensin S, Bonafe M, Paolisso G, Yashin AI, Monti D, De Benedictis G (2000) The network and the remodeling theories of aging: historical background and new perspectives. Exp Gerontol 35:879-896

2. Xu W, Wong G, Hwang YY, Larbi A (2020) The untwining of immunosenescence and aging. Semin Immunopathol 42:559-572

3. Krenzien F, ElKhal A, Quante M, Rodriguez Cetina Biefer H, Hirofumi U, Gabardi S, Tullius SG (2015) A rationale for ageadapted immunosuppression in organ transplantation. Transplantation 99:2258-2268

4. Monneret G, Gossez M, Venet F (2019) Sepsis and immunosenescence: closely associated in a vicious circle. Aging Clin Exp Res. https://doi.org/10.1007/s40520-019-01350-Z

5. Lian J, Yue Y, Yu W, Zhang Y (2020) Immunosenescence: a key player in cancer development. J Hematol Oncol 13:151

6. Hernandez-Segura A, Nehme J, Demaria M (2018) Hallmarks of cellular senescence. Trends Cell Biol 28:436-453

7. Gentile LF, Cuenca AG, Efron PA, Ang D, Bihorac A, McKinley BA, Moldawer LL, Moore FA (2012) Persistent inflammation and immunosuppression: a common syndrome and new horizon for surgical intensive care. J Trauma Acute Care Surg 72:1491-1501

8. Kanterman J, Sade-Feldman M, Baniyash M (2012) New insights into chronic inflammation-induced immunosuppression. Semin Cancer Biol 22:307-318

9. Amodio G, Cichy J, Conde P, Matteoli G, Moreau A, Ochando J, Oral BH, Pekarova M, Ryan EJ, Roth J et al (2019) Role of myeloid regulatory cells (MRCs) in maintaining tissue homeostasis and promoting tolerance in autoimmunity, inflammatory disease and transplantation. Cancer Immunol Immunother 68:661-672

10. Gabrilovich DI, Nagaraj S (2009) Myeloid-derived suppressor cells as regulators of the immune system. Nat Rev Immunol 9:162-174

11. Pawelec G (2020) The human immunosenescence phenotype: does it exist? Semin Immunopathol 42:537-544

12. Ye J, Huang X, Hsueh EC, Zhang Q, Ma C, Zhang Y, Varvares MA, Hoft DF, Peng G (2012) Human regulatory T cells induce T-lymphocyte senescence. Blood 120:2021-2031

13. Liu X, Mo W, Ye J, Li L, Zhang Y, Hsueh EC, Hoft DF, Peng G (2018) Regulatory T cells trigger effector T cell DNA damage and senescence caused by metabolic competition. Nat Commun 9:249

14. Gayoso I, Sanchez-Correa B, Campos C, Alonso C, Pera A, Casado JG, Morgado S, Tarazona R, Solana R (2011) Immunosenescence of human natural killer cells. J Innate Immun 3:337-343

15. Fulop T, Dupuis G, Witkowski JM, Larbi A (2016) The role of immunosenescence in the development of age-related diseases. Rev Invest Clin 68:84-91

16. Barbe-Tuana F, Funchal G, Schmitz CRR, Maurmann RM, Bauer ME (2020) The interplay between immunosenescence and agerelated diseases. Semin Immunopathol 42:545-557

17. Fulop T, Larbi A, Dupuis G, Le Page A, Frost EH, Cohen AA, Witkowski JM, Franceschi C (2018) Immunosenescence and inflamm-aging as two sides of the same coin: friends or foes? Front Immunol 8:1960

18. Akbar AN, Henson SM (2011) Are senescence and exhaustion intertwined or unrelated processes that compromise immunity? Nat Rev Immunol 11:289-295

19. Zhao Y, Shao Q, Peng G (2020) Exhaustion and senescence: two crucial dysfunctional states of T cells in the tumor microenvironment. Cell Mol Immunol 17:27-35 
20. Wang S, Zhang Q, Hui H, Agrawal K, Karris MAY, Rana TM (2020) An atlas of immune cell exhaustion in HIV-infected individuals revealed by single-cell transcriptomics. Emerg Microbes Infect 9:2333-2347

21. Lee J, Ahn E, Kissick HT, Ahmed R (2015) Reinvigorating exhausted $\mathrm{T}$ cells by blockade of the PD-1 pathway. For Immunopathol Dis Therap 6:7-17

22. Judge SJ, Murphy WJ, Canter RJ (2020) Characterizing the dysfunctional NK cell: assessing the clinical relevance of exhaustion, anergy, and senescence. Front Cell Infect Microbiol 10:49

23. Pawelec G, Remarque E, Barnett Y, Solana R (1998) T cells and aging. Front Biosci 3:d59-d99

24. Salminen A, Kaarniranta K, Kauppinen A (2019) Immunosenescence: the potential role of myeloid-derived suppressor cells (MDSC) in age-related immune deficiency. Cell Mol Life Sci 76:1901-1918

25. Rodriguez IJ, Lalinde Ruiz N, Llano Leon M, Martínez Enriquez L, Montilla Velasquez MDP, Ortiz Aguirre JP, Rodriguez Bohorquez OM, Velandia Vargas EA, Hernandez ED, Parra Lopez CA (2021) Immunosenescence study of T cells: a systematic review. Front Immunol 11:604591

26. Vallejo AN (2007) Immune remodeling: lessons from repertoire alterations during chronological aging and in immune-mediated disease. Trends Mol Med 13:94-102

27. Pang WW, Price EA, Sahoo D, Beerman I, Maloney WJ, Rossi DJ, Schrier SL, Weissman IL (2011) Human bone marrow hematopoietic stem cells are increased in frequency and myeloidbiased with age. Proc Natl Acad Sci U S A 108:20012-20017

28. Egorov ES, Kasatskaya SA, Zubov VN, Izraelson M, Nakonechnaya TO, Staroverov DB, Angius A, Cucca F, Mamedov IZ, Rosati E et al (2018) The changing landscape of naive T cell receptor repertoire with human aging. Front Immunol 9:1618

29. Kennedy DE, Knight KL (2015) Inhibition of B lymphopoiesis by adipocytes and IL-1-producing myeloid-derived suppressor cells. J Immunol 195:2666-2674

30. Li MO, Wan YY, Sanjabi S, Robertson AK, Flavell RA (2006) Transforming growth factor- $\beta$ regulation of immune responses. Annu Rev Immunol 24:99-146

31. Frasca D, Diaz A, Romero M, Garcia D, Blomberg BB (2020) B cell immunosenescence. Annu Rev Cell Dev Biol 36:551-574

32. Sagiv A, Burton DG, Moshayev Z, Vadai E, Wensveen F, BenDor S, Golani O, Polic B, Krizhanovsky V (2016) NKG2D ligands mediate immunosurveillance of senescent cells. Aging (Albany NY) 8:328-344

33. Salminen A (2021) Feed-forward regulation between cellular senescence and immunosuppression promotes the aging process and age-related diseases. Ageing Res Rev 67:101280

34. Hazeldine J, Lord JM (2013) The impact of ageing on natural killer cell function and potential consequences for health in older adults. Ageing Res Rev 12:1069-1078

35. Almeida-Oliveira A, Smith-Carvalho M, Porto LC, CardosoOliveira J, Ribeiro Ados S, Falcao RR, Abdelhay E, Bouzas LF, Thuler LC, Ornellas MH et al (2011) Age-related changes in natural killer cell receptors from childhood through old age. Hum Immunol 72:319-329

36. Kared H, Martelli S, Ng TP, Pender SL, Larbi A (2016) CD57 in human natural killer cells and T-lymphocytes. Cancer Immunol Immunother 65:441-452

37. Hazeldine J, Hampson P, Lord JM (2012) Reduced release and binding of perforin at the immunological synapse underlies the age-related decline in natural killer cell cytotoxicity. Aging Cell 11:751-759

38. Rajagopalan S, Long EO (2012) Cellular senescence induced by CD158d reprograms natural killer cells to promote vascular remodeling. Proc Natl Acad Sci U S A 109:20596-20601
39. Stout RD, Suttles J (2005) Immunosenescence and macrophage functional plasticity: dysregulation of macrophage function by age-associated microenvironmental changes. Immunol Rev 205:60-71

40. Bhushan M, Cumberbatch M, Dearman RJ, Andrew SM, Kimber I, Griffiths CE (2002) Tumour necrosis factor- $\alpha$-induced migration of human Langerhans cells: the influence of ageing. $\mathrm{Br} \mathbf{J}$ Dermatol 146:32-40

41. Agrawal A, Gupta S (2011) Impact of aging on dendritic cell functions in humans. Ageing Res Rev 10:336-345

42. Chougnet CA, Thacker RI, Shehata HM, Hennies CM, Lehn MA, Lages CS, Janssen EM (2015) Loss of phagocytic and antigen cross-presenting capacity in aging dendritic cells is associated with mitochondrial dysfunction. J Immunol 195:2624-2632

43. Panda A, Qian F, Mohanty S, van Duin D, Newman FK, Zhang L, Chen S, Towle V, Belshe RB, Fikrig E et al (2010) Age-associated decrease in TLR function in primary human dendritic cells predicts influenza vaccine response. J Immunol 184:2518-2527

44. Linehan E, Fitzgerald DC (2015) Ageing and the immune system: focus on macrophages. Eur J Microbiol Immunol (Bp) 5:14-24

45. De Maeyer RPH, Chambers ES (2021) The impact of ageing on monocytes and macrophages. Immunol Lett 230:1-10

46. Kohut ML, Senchina DS, Madden KS, Martin AE, Felten DL, Moynihan JA (2004) Age effects on macrophage function vary by tissue site, nature of stimulant, and exercise behavior. Exp Gerontol 39:1347-1360

47. Akbar AN, Henson SM, Lanna A (2016) Senescence of T lymphocytes: implications for enhancing human immunity. Trends Immunol 37:866-876

48. Behmoaras J, Gil J (2021) Similarities and interplay between senescent cells and macrophages. J Cell Biol 220:e202010162

49. Liu Y, Sanoff HK, Cho H, Burd CE, Torrice C, Ibrahim JG, Thomas NE, Sharpless NE (2009) Expression of p16(INK4a) in peripheral blood T-cells is a biomarker of human aging. Aging Cell 8:439-448

50. Onyema OO, Njemini R, Bautmans I, Renmans W, De Waele M, Mets T (2012) Cellular aging and senescence characteristics of human T-lymphocytes. Biogerontology 13:169-181

51. Mondal AM, Horikawa I, Pine SR, Fujita K, Morgan KM, Vera E, Mazur SJ, Appella E, Vojtesek B, Blasco MA et al (2013) p53 isoforms regulate aging- and tumor-associated replicative senescence in T lymphocytes. J Clin Invest 123:5247-5257

52. Rajagopalan S, Lee EC, DuPrie ML, Long EO (2014) TNFRassociated factor 6 and TGF- $\beta$-activated kinase 1 control signals for a senescence response by an endosomal NK cell receptor. $\mathrm{J}$ Immunol 192:714-721

53. Hall BM, Balan V, Gleiberman AS, Strom E, Krasnov P, Virtuoso LP, Rydkina E, Vujcic S, Balan K, Gitlin I et al (2016) Aging of mice is associated with p16(Ink4a)- and $\beta$-galactosidase-positive macrophage accumulation that can be induced in young mice by senescent cells. Aging (Albany NY) 8:1294-1315

54. Liu JY, Souroullas GP, Diekman BO, Krishnamurthy J, Hall BM, Sorrentino JA, Parker JS, Sessions GA, Gudkov AV, Sharpless NE (2019) Cells exhibiting strong p16INK4a promoter activation in vivo display features of senescence. Proc Natl Acad Sci U S A 116:2603-2611

55. Wang H, Fu H, Zhu R, Wu X, Ji X, Li X, Jiang H, Lin Z, Tang $X$, Sun $S$ et al (2020) BRD4 contributes to LPS-induced macrophage senescence and promotes progression of atherosclerosisassociated lipid uptake. Aging (Albany NY) 12:9240-9259

56. Gerland LM, Genestier L, Peyrol S, Michallet MC, Hayette S, Urbanowicz I, Ffrench P, Magaud JP, Ffrench M (2004) Autolysosomes accumulate during in vitro $\mathrm{CD} 8^{+} \mathrm{T}$-lymphocyte aging and may participate in induced death sensitization of senescent cells. Exp Gerontol 39:789-800 
57. Covre LP, Martins RF, Devine OP, Chambers ES, VukmanovicStejic M, Silva JA, Dietze R, Rodrigues RR, de Matos Guedes HL, Falqueto A et al (2019) Circulating senescent $T$ cells are linked to systemic inflammation and lesion size during human cutaneous Leishmaniasis. Front Immunol 9:3001

58. Kaszubowska L (2008) Telomere shortening and ageing of the immune system. J Physiol Pharmacol 59(Suppl 9):169-186

59. Sebastian C, Herrero C, Serra M, Lloberas J, Blasco MA, Celada A (2009) Telomere shortening and oxidative stress in aged macrophages results in impaired STAT5a phosphorylation. J Immunol 183:2356-2364

60. Sanderson SL, Simon AK (2017) In aged primary T cells, mitochondrial stress contributes to telomere attrition measured by a novel imaging flow cytometry assay. Aging Cell 16:1234-1243

61. Stranks AJ, Hansen AL, Panse I, Mortensen M, Ferguson DJ, Puleston DJ, Shenderov K, Watson AS, Veldhoen M, Phadwal $\mathrm{K}$ et al (2015) Autophagy controls acquisition of aging features in macrophages. J Innate Immun 7:375-391

62. Zhang H, Puleston DJ, Simon AK (2016) Autophagy and immune senescence. Trends Mol Med 22:671-686

63. Bektas A, Schurman SH, Gonzalez-Freire M, Dunn CA, Singh AK, Macian F, Cuervo AM, Sen R, Ferrucci L (2019) Ageassociated changes in human $\mathrm{CD}^{+}{ }^{+} \mathrm{T}$ cells point to mitochondrial dysfunction consequent to impaired autophagy. Aging (Albany NY) 11:9234-9263

64. Hurst KE, Lawrence KA, Essman MT, Walton ZJ, Leddy LR, Thaxton JE (2019) Endoplasmic reticulum stress contributes to mitochondrial exhaustion of $\mathrm{CD}^{+} \mathrm{T}$ cells. Cancer Immunol Res 7:476-486

65. Sukhorukov VN, Khotina VA, Bagheri Ekta M, Ivanova EA, Sobenin IA, Orekhov AN (2020) Endoplasmic reticulum stress in macrophages: the vicious circle of lipid accumulation and proinflammatory response. Biomedicines 8:210

66. Kannan S, Dawany N, Kurupati R, Showe LC, Ertl HC (2016) Age-related changes in the transcriptome of antibody-secreting cells. Oncotarget 7:13340-13353

67. Vida C, de Toda IM, Cruces J, Garrido A, Gonzalez-Sanchez M, De la Fuente M (2017) Role of macrophages in age-related oxidative stress and lipofuscin accumulation in mice. Redox Biol $12: 423-437$

68. Garrido A, Cruces J, Ceprian N, Vara E, de la Fuente M (2019) Oxidative-inflammatory stress in immune cells from adult mice with premature aging. Int J Mol Sci 20:769

69. Martinez de Toda I, Vida C, Sanz San Miguel L, De la Fuente M (2019) Function, oxidative, and inflammatory stress parameters in immune cells as predictive markers of lifespan throughout aging. Oxid Med Cell Longev 2019:4574276

70. Callender LA, Carroll EC, Beal RWJ, Chambers ES, Nourshargh S, Akbar AN, Henson SM (2018) Human CD8 ${ }^{+}$EMRA T cells display a senescence-associated secretory phenotype regulated by p38 MAPK. Aging Cell 17:e12675

71. Frasca D, Diaz A, Romero M, Blomberg BB (2017) Human peripheral late/exhausted memory B cells express a senescentassociated secretory phenotype and preferentially utilize metabolic signaling pathways. Exp Gerontol 87:113-120

72. Salminen A, Kauppinen A, Kaarniranta K (2012) Emerging role of NF- $\mathrm{KB}$ signaling in the induction of senescence-associated secretory phenotype (SASP). Cell Signal 24:835-845

73. Kaltschmidt B, Kaltschmidt C, Hofmann TG, Hehner SP, Dröge W, Schmitz ML (2000) The pro- or anti-apoptotic function of $\mathrm{NF}-\kappa \mathrm{B}$ is determined by the nature of the apoptotic stimulus. Eur J Biochem 267:3828-3835

74. Salminen A, Ojala J, Kaarniranta K (2011) Apoptosis and aging: increased resistance to apoptosis enhances the aging process. Cell Mol Life Sci 68:1021-1031
75. Spaulding C, Guo W, Effros RB (1999) Resistance to apoptosis in human $\mathrm{CD} 8^{+} \mathrm{T}$ cells that reach replicative senescence after multiple rounds of antigen-specific proliferation. Exp Gerontol 34:633-644

76. Dennett NS, Barcia RN, McLeod JD (2002) Age associated decline in CD25 and CD28 expression correlate with an increased susceptibility to CD95 mediated apoptosis in T cells. Exp Gerontol 37:271-283

77. Chong Y, Ikematsu H, Yamaji K, Nishimura M, Nabeshima S, Kashiwagi S, Hayashi J (2005) CD27 $7^{+}$(memory) B cell decrease and apoptosis-resistant $\mathrm{CD} 27^{-}$(naive) B cell increase in aged humans: implications for age-related peripheral B cell developmental disturbances. Int Immunol 17:383-390

78. Bauer ME (2020) Accelerated immunosenescence in rheumatoid arthritis: impact on clinical progression. Immun Ageing 17:6

79. Weyand CM, Yang Z, Goronzy JJ (2014) T-cell aging in rheumatoid arthritis. Curr Opin Rheumatol 26:93-100

80. Cunha LL, Perazzio SF, Azzi J, Cravedi P, Riella LV (2020) Remodeling of the immune response with aging: immunosenescence and its potential impact on COVID-19 immune response. Front Immunol 11:1748

81. Shirakawa K, Yan X, Shinmura K, Endo J, Kataoka M, Katsumata Y, Yamamoto T, Anzai A, Isobe S, Yoshida N et al (2016) Obesity accelerates $\mathrm{T}$ cell senescence in murine visceral adipose tissue. $\mathrm{J}$ Clin Invest 126:4626-4639

82. Bauer ME, Teixeira AL (2019) Inflammation in psychiatric disorders: what comes first? Ann NY Acad Sci 1437:57-67

83. Bauer ME, Teixeira AL (2021) Neuroinflammation in mood disorders: role of regulatory immune cells. NeuroImmunoModulation. https://doi.org/10.1159/000515594

84. Gelson W, Hoare M, Vowler S, Shankar A, Gibbs P, Akbar AN, Alexander GJ (2010) Features of immune senescence in liver transplant recipients with established grafts. Liver Transpl $16: 577-587$

85. Lecot P, Alimirah F, Desprez PY, Campisi J, Wiley C (2016) Context-dependent effects of cellular senescence in cancer development. Br J Cancer 114:1180-1184

86. Sanchez-Correa B, Campos C, Pera A, Bergua JM, Arcos MJ, Banas H, Casado JG, Morgado S, Duran E, Solana R et al (2016) Natural killer cell immunosenescence in acute myeloid leukaemia patients: new targets for immunotherapeutic strategies? Cancer Immunol Immunother 65:453-463

87. Wang D, DuBois RN (2015) Immunosuppression associated with chronic inflammation in the tumor microenvironment. Carcinogenesis 36:1085-1093

88. Ferrer IR, Hester J, Bushell A, Wood KJ (2014) Induction of transplantation tolerance through regulatory cells: from mice to men. Immunol Rev 258:102-116

89. Sacchi A, Grassi G, Bordoni V, Lorenzini P, Cimini E, Casetti R, Tartaglia E, Marchioni L, Petrosillo N, Palmieri F et al (2020) Early expansion of myeloid-derived suppressor cells inhibits SARS-CoV-2 specific T-cell response and may predict fatal COVID-19 outcome. Cell Death Dis 11:921

90. Mira JC, Brakenridge SC, Moldawer LL, Moore FA (2017) Persistent inflammation, immunosuppression and catabolism syndrome. Crit Care Clin 33:245-258

91. Lindau D, Gielen P, Kroesen M, Wesseling P, Adema GJ (2013) The immunosuppressive tumour network: myeloidderived suppressor cells, regulatory $\mathrm{T}$ cells and natural killer T cells. Immunology 138:105-115

92. Salminen A (2020) Activation of immunosuppressive network in the aging process. Ageing Res Rev 57:100998

93. Nagaraj S, Youn JI, Gabrilovich DI (2013) Reciprocal relationship between myeloid-derived suppressor cells and $\mathrm{T}$ cells. $\mathrm{J}$ Immunol 191:17-23 
94. Park YJ, Song B, Kim YS, Kim EK, Lee JM, Lee GE, Kim JO, Kim YJ, Chang WS, Kang CY (2013) Tumor microenvironmental conversion of natural killer cells into myeloid-derived suppressor cells. Cancer Res 73:5669-5681

95. Sorokin L (2010) The impact of the extracellular matrix on inflammation. Nat Rev Immunol 10:712-723

96. Ouyang W, Rutz S, Crellin NK, Valdez PA, Hymowitz SG (2011) Regulation and functions of the IL-10 family of cytokines in inflammation and disease. Annu Rev Immunol 29:71-109

97. Whiteside TL, Jackson EK (2013) Adenosine and prostaglandin e2 production by human inducible regulatory $\mathrm{T}$ cells in health and disease. Front Immunol 4:212

98. Salminen A (2021) Increased immunosuppression impairs tissue homeostasis with aging and age-related diseases. J Mol Med (Berl) 99:1-20

99. Regis S, Dondero A, Caliendo F, Bottino C, Castriconi R (2020) NK cell function regulation by TGF- $\beta$-induced epigenetic mechanisms. Front Immunol 11:311

100. Tominaga K, Suzuki HI (2019) TGF- $\beta$ signaling in cellular senescence and aging-related pathology. Int J Mol Sci 20:5002

101. Nakamura K, Matsunaga K (1998) Susceptibility of natural killer (NK) cells to reactive oxygen species (ROS) and their restoration by the mimics of superoxide dismutase (SOD). Cancer Biother Radiopharm 13:275-290

102. Nagaraj S, Gupta K, Pisarev V, Kinarsky L, Sherman S, Kang L, Herber DL, Schneck J, Gabrilovich DI (2007) Altered recognition of antigen is a mechanism of $\mathrm{CD}^{+} \mathrm{T}$ cell tolerance in cancer. Nat Med 13:828-835

103. Davalli P, Mitic T, Caporali A, Lauriola A, D'Arca D (2016) ROS, cell senescence, and novel molecular mechanisms in aging and age-related diseases. Oxid Med Cell Longev 2016:3565127

104. Holt D, Ma X, Kundu N, Fulton A (2011) Prostaglandin E2 (PGE2) suppresses natural killer cell function primarily through the PGE2 receptor EP4. Cancer Immunol Immunother 60:1577-1586

105. Gomez I, Foudi N, Longrois D, Norel X (2013) The role of prostaglandin E2 in human vascular inflammation. Prostaglandins Leukot Essent Fatty Acids 89:55-63

106. Mackay IR (1972) Ageing and immunological function in man. Gerontologia 18:285-304

107. Roder JC, Duwe AK, Bell DA, Singhal SK (1978) Immunological senescence. I. The role of suppressor cells Immunology 35:837-847

108. Singhal SK, Roder JC, Duwe AK (1978) Suppressor cells in immunosenescence. Fed Proc 37:1245-1252

109. Gregg R, Smith CM, Clark FJ, Dunnion D, Khan N, Chakraverty R, Nayak L, Moss PA (2005) The number of human peripheral blood $\mathrm{CD} 4{ }^{+} \mathrm{CD} 25^{\text {high }}$ regulatory $\mathrm{T}$ cells increases with age. Clin Exp Immunol 140:540-546

110. Lages CS, Suffia I, Velilla PA, Huang B, Warshaw G, Hildeman DA, Belkaid Y, Chougnet C (2008) Functional regulatory T cells accumulate in aged hosts and promote chronic infectious disease reactivation. J Immunol 181:1835-1848

111. Sharma S, Dominguez AL, Lustgarten J (2006) High accumulation of T regulatory cells prevents the activation of immune responses in aged animals. J Immunol 177:8348-8355

112. Verschoor CP, Johnstone J, Millar J, Dorrington MG, Habibagahi M, Lelic A, Loeb M, Bramson JL, Bowdish DM (2013) Blood $\mathrm{CD}^{+}{ }^{+} \mathrm{HLA}^{-} \mathrm{DR}^{-}$myeloid-derived suppressor cells are increased with age and a history of cancer. J Leukoc Biol 93:633-637

113. Enioutina EY, Bareyan D, Daynes RA (2011) A role for immature myeloid cells in immune senescence. J Immunol 186:697-707

114. Jackaman C, Radley-Crabb HG, Soffe Z, Shavlakadze T, Grounds MD, Nelson DJ (2013) Targeting macrophages rescues agerelated immune deficiencies in C57BL/6J geriatric mice. Aging Cell 12:345-357
115. Wang Y, Wehling-Henricks M, Samengo G, Tidball JG (2015) Increases of $\mathrm{M} 2 \mathrm{a}$ macrophages and fibrosis in aging muscle are influenced by bone marrow aging and negatively regulated by muscle-derived nitric oxide. Aging Cell 14:678-688

116. Agius E, Lacy KE, Vukmanovic-Stejic M, Jagger AL, Papageorgiou AP, Hall S, Reed JR, Curnow SJ, Fuentes-Duculan J, Buckley CD et al (2009) Decreased TNF- $\alpha$ synthesis by macrophages restricts cutaneous immunosurveillance by memory $\mathrm{CD} 4^{+} \mathrm{T}$ cells during aging. J Exp Med 206:1929-1940

117. Kalathookunnel Antony A, Lian Z, Wu H (2018) T cells in adipose tissue in aging. Front Immunol 9:2945

118. Ruhland MK, Loza AJ, Capietto AH, Luo X, Knolhoff BL, Flanagan KC, Belt BA, Alspach E, Leahy K, Luo J et al (2016) Stromal senescence establishes an immunosuppressive microenvironment that drives tumorigenesis. Nat Commun 7:11762

119. Tcyganov E, Mastio J, Chen E, Gabrilovich DI (2018) Plasticity of myeloid-derived suppressor cells in cancer. Curr Opin Immunol 51:76-82

120. Chen J, Ye Y, Liu P, Yu W, Wei F, Li H, Yu J (2017) Suppression of $\mathrm{T}$ cells by myeloid-derived suppressor cells in cancer. Hum Immunol 78:113-119

121. Özkan B, Lim H, Park SG (2018) Immunomodulatory function of myeloid-derived suppressor cells during B cell-mediated immune responses. Int J Mol Sci 19:1468

122. Park MJ, Lee SH, Kim EK, Lee EJ, Baek JA, Park SH, Kwok SK, Cho ML (2018) Interleukin-10 produced by myeloidderived suppressor cells is critical for the induction of Tregs and attenuation of rheumatoid inflammation in mice. Sci Rep $8: 3753$

123. Park MJ, Lee SH, Kim EK, Lee EJ, Park SH, Kwok SK, Cho ML (2016) Myeloid-derived suppressor cells induce the expansion of regulatory B cells and ameliorate autoimmunity in the Sanroque mouse model of systemic lupus erythematosus. Arthritis Rheumatol 68:2717-2727

124. Poschke I, Mao Y, Adamson L, Salazar-Onfray F, Masucci G, Kiessling R (2012) Myeloid-derived suppressor cells impair the quality of dendritic cell vaccines. Cancer Immunol Immunother 61:827-838

125. Hu CE, Gan J, Zhang RD, Cheng YR, Huang GJ (2011) Upregulated myeloid-derived suppressor cell contributes to hepatocellular carcinoma development by impairing dendritic cell function. Scand J Gastroenterol 46:156-164

126. Hoechst B, Voigtlaender T, Ormandy L, Gamrekelashvili J, Zhao F, Wedemeyer H, Lehner F, Manns MP, Greten TF, Korangy F (2009) Myeloid derived suppressor cells inhibit natural killer cells in patients with hepatocellular carcinoma via the NKp30 receptor. Hepatology 50:799-807

127. Fortin C, Huang X, Yang Y (2012) NK cell response to vaccinia virus is regulated by myeloid-derived suppressor cells. J Immunol 189:1843-1849

128. Ostrand-Rosenberg S, Sinha P, Beury DW, Clements VK (2012) Cross-talk between myeloid-derived suppressor cells (MDSC), macrophages, and dendritic cells enhances tumor-induced immune suppression. Semin Cancer Biol 22:275-281

129. Nguyen HH, Tran BT, Muller W, Jack RS (2012) IL-10 acts as a developmental switch guiding monocyte differentiation to macrophages during a murine peritoneal infection. J Immunol 189:3112-3120

130. Ye J, Ma C, Hsueh EC, Eickhoff CS, Zhang Y, Varvares MA, Hoft DF, Peng G (2013) Tumor-derived $\gamma \delta$ regulatory T cells suppress innate and adaptive immunity through the induction of immunosenescence. J Immunol 190:2403-2414

131. Trzonkowski P, Szmit E, Mysliwska J, Mysliwski A (2006) CD4+CD25+ T regulatory cells inhibit cytotoxic activity of CTL and NK cells in humans-impact of immunosenescence. Clin Immunol 119:307-316 
132. Ralainirina N, Poli A, Michel T, Poos L, Andres E, Hentges F, Zimmer J (2007) Control of NK cell functions by $\mathrm{CD} 4^{+} \mathrm{CD} 25^{+}$ regulatory T cells. J Leukoc Biol 81:144-153

133. Pereira BI, Devine OP, Vukmanovic-Stejic M, Chambers ES, Subramanian P, Patel N, Virasami A, Sebire NJ, Kinsler V, Valdovinos A et al (2019) Senescent cells evade immune clearance via HLA-E-mediated $\mathrm{NK}$ and $\mathrm{CD} 8^{+} \mathrm{T}$ cell inhibition. Nat Commun 10:2387

134. Li H, Han Y, Guo Q, Zhang M, Cao X (2009) Cancer-expanded myeloid-derived suppressor cells induce anergy of NK cells through membrane-bound TGF- $\beta 1$. J Immunol 182:240-249

135. Delisle JS, Giroux M, Boucher G, Landry JR, Hardy MP, Lemieux S, Jones RG, Wilhelm BT, Perreault C (2013) The TGF- $\beta$-Smad3 pathway inhibits CD28-dependent cell growth and proliferation of CD4 T cells. Genes Immun 14:115-126

136. Tiemessen MM, Kunzmann S, Schmidt-Weber CB, Garssen J, Bruijnzeel-Koomen CA, Knol EF, van Hoffen E (2003) Transforming growth factor- $\beta$ inhibits human antigen-specific $\mathrm{CD} 4^{+}$ $\mathrm{T}$ cell proliferation without modulating the cytokine response. Int Immunol 15:1495-1504

137. Viel S, Marcais A, Guimaraes FS, Loftus R, Rabilloud J, Grau M, Degouve S, Djebali S, Sanlaville A, Charrier E et al (2016) TGF- $\beta$ inhibits the activation and functions of NK cells by repressing the mTOR pathway. Sci Signal 9:ra19

138. Iwasa H, Han J, Ishikawa F (2003) Mitogen-activated protein kinase $\mathrm{p} 38$ defines the common senescence-signalling pathway. Genes Cells 8:131-144

139. Lanna A, Henson SM, Escors D, Akbar AN (2014) The kinase p38 activated by the metabolic regulator AMPK and scaffold TAB 1 drives the senescence of human T cells. Nat Immunol 15:965-972

140. Yu L, Hebert MC, Zhang YE (2002) TGF- $\beta$ receptor-activated p38 MAP kinase mediates Smad-independent TGF- $\beta$ responses. EMBO J 21:3749-3759

141. Henson SM, Lanna A, Riddell NE, Franzese O, Macaulay R, Griffiths SJ, Puleston DJ, Watson AS, Simon AK, Tooze SA et al (2014) p38 signaling inhibits mTORC1-independent autophagy in senescent human CD8 T cells. J Clin Invest 124:4004-4016

142. Lanna A, Gomes DC, Muller-Durovic B, McDonnell T, Escors D, Gilroy DW, Lee JH, Karin M, Akbar AN (2017) A sestrindependent Erk-Jnk-p38 MAPK activation complex inhibits immunity during aging. Nat Immunol 18:354-363

143. Ding N, Dahlke K, Janze AK, Mailer PC, Maus R, Bohling J, Welte T, Bauer M, Riedemann NC, Maus UA (2012) Role of p38 mitogen-activated protein kinase in posttraumatic immunosuppression in mice. J Trauma Acute Care Surg 73:861-868

144. Freund A, Patil CK, Campisi J (2011) p38MAPK is a novel DNA damage response-independent regulator of the senescence-associated secretory phenotype. EMBO J 30:1536-1548

145. Murray PJ (2016) Amino acid auxotrophy as a system of immunological control nodes. Nat Immunol 17:132-139

146. Castilho BA, Shanmugam R, Silva RC, Ramesh R, Himme BM, Sattlegger E (2014) Keeping the eIF2 $\alpha$ kinase Gcn2 in check. Biochim Biophys Acta 1843:1948-1968

147. Munn DH, Sharma MD, Baban B, Harding HP, Zhang Y, Ron D, Mellor AL (2005) GCN2 kinase in T cells mediates proliferative arrest and anergy induction in response to indoleamine 2,3-dioxygenase. Immunity 22:633-642

148. Mandi Y, Vecsei L (2012) The kynurenine system and immunoregulation. J Neural Transm (Vienna) 119:197-209

149. Holmgaard RB, Zamarin D, Li Y, Gasmi B, Munn DH, Allison JP, Merghoub T, Wolchok JD (2015) Tumor-expressed IDO recruits and activates MDSCs in a Treg-dependent manner. Cell Rep $13: 412-424$
150. Rad Pour S, Morikawa H, Kiani NA, Yang M, Azimi A, Shafi G, Shang M, Baumgartner R, Ketelhuth DFJ, Kamleh MA et al (2019) Exhaustion of CD4 ${ }^{+}$T-cells mediated by the kynurenine pathway in melanoma. Sci Rep 9:12150

151. Fallarino F, Grohmann U, Vacca C, Bianchi R, Orabona C, Spreca A, Fioretti MC, Puccetti P (2002) T cell apoptosis by tryptophan catabolism. Cell Death Differ 9:1069-1077

152. Della Chiesa M, Carlomagno S, Frumento G, Balsamo M, Cantoni C, Conte R, Moretta L, Moretta A, Vitale M (2006) The tryptophan catabolite L-kynurenine inhibits the surface expression of NKp46- and NKG2D-activating receptors and regulates NK-cell function. Blood 108:4118-4125

153. Mezrich JD, Fechner JH, Zhang X, Johnson BP, Burlingham WJ, Bradfield CA (2010) An interaction between kynurenine and the aryl hydrocarbon receptor can generate regulatory $\mathrm{T}$ cells. $\mathbf{J}$ Immunol 185:3190-3198

154. Kondrikov D, Elmansi A, Bragg RT, Mobley T, Barrett T, Eisa N, Kondrikova G, Schoeinlein P, Aguilar-Perez A, Shi $\mathrm{XM}$ et al (2020) Kynurenine inhibits autophagy and promotes senescence in aged bone marrow mesenchymal stem cells through the aryl hydrocarbon receptor pathway. Exp Gerontol 130:110805

155. Sorgdrager FJH, Naude PJW, Kema IP, Nollen EA, Deyn PP (2019) Tryptophan metabolism in inflammaging: from biomarker to therapeutic target. Front Immunol 10:2565

156. Baumgartner R, Forteza MJ, Ketelhuth DFJ (2019) The interplay between cytokines and the kynurenine pathway in inflammation and atherosclerosis. Cytokine 122:154148

157. Campesato LF, Budhu S, Tchaicha J, Weng CH, Gigoux M, Cohen IJ, Redmond D, Mangarin L, Pourpe S, Liu C et al (2020) Blockade of the AHR restricts a Treg-macrophage suppressive axis induced by L-kynurenine. Nat Commun 11:4011

158. Neamah WH, Singh NP, Alghetaa H, Abdulla OA, Chatterjee S, Busbee PB, Nagarkatti M, Nagarkatti P (2019) AhR activation leads to massive mobilization of myeloid-derived suppressor cells with immunosuppressive activity through regulation of CXCR2 and microRNA miR-150-5p and miR-543-3p that target anti-inflammatory genes. J Immunol 203:1830-1844

159. Wang H, Wei Y, Yu D (2015) Control of lymphocyte homeostasis and effector function by the aryl hydrocarbon receptor. Int Immunopharmacol 28:818-824

160. Alvarez-Errico D, Vento-Tormo R, Sieweke M, Ballestar E (2015) Epigenetic control of myeloid cell differentiation, identity and function. Nat Rev Immunol 15:7-17

161. Mikami N, Kawakami R, Chen KY, Sugimoto A, Ohkura N, Sakaguchi S (2020) Epigenetic conversion of conventional T cells into regulatory T cells by CD28 signal deprivation. Proc Natl Acad Sci U S A 117:12258-12268

162. Yang N, Sen $P$ (2018) The senescent cell epigenome Aging (Albany NY) 10:3590-3609

163. Zhang W, Qu J, Liu GH, Belmonte JCI (2020) The ageing epigenome and its rejuvenation. Nat Rev Mol Cell Biol 21:137-150

164. Salminen A, Kaarniranta K, Hiltunen M, Kauppinen A (2014) Histone demethylase Jumonji D3 (JMJD3/KDM6B) at the nexus of epigenetic regulation of inflammation and the aging process. J Mol Med (Berl) 92:1035-1043

165. Andriani GA, Almeida VP, Faggioli F, Mauro M, Tsai WL, Santambrogio L, Maslov A, Gadina M, Campisi J, Vijg J et al (2016) Whole chromosome instability induces senescence and promotes SASP. Sci Rep 6:35218

166. Lyu G, Guan Y, Zhang C, Zong L, Sun L, Huang X, Huang L, Zhang L, Tian XL, Zhou $Z$ et al (2018) TGF- $\beta$ signaling alters H4K20me3 status via miR-29 and contributes to cellular senescence and cardiac aging. Nat Commun 9:2560 
167. Gaarenstroom T, Hill CS (2014) TGF- $\beta$ signaling to chromatin: how Smads regulate transcription during self-renewal and differentiation. Semin Cell Dev Biol 32:107-118

168. Wang YQ, Li YM, Li X, Liu T, Liu XK, Zhang JQ, Guo JW, Guo LY, Qiao L (2013) Hypermethylation of TGF- $\beta 1$ gene promoter in gastric cancer. World J Gastroenterol 19:5557-5564

169. Tian CQ, Chen L, Chen HD, Huan XJ, Hu JP, Shen JK, Xiong B, Wang YQ, Miao ZH (2019) Inhibition of the BET family reduces its new target gene IDO1 expression and the production of L-kynurenine. Cell Death Dis 10:557

170. Zhang H, Kuchroo V (2019) Epigenetic and transcriptional mechanisms for the regulation of IL-10. Semin Immunol 44:101324

171. Wajda A, Lapczuk-Romanska J, Paradowska-Gorycka A (2020) Epigenetic regulations of AhR in the aspect of immunomodulation. Int J Mol Sci 21:6404

172. Huehn J, Beyer M (2015) Epigenetic and transcriptional control of Foxp $3^{+}$regulatory T cells. Semin Immunol 27:10-18

173. Zhao M, Qin J, Yin H, Tan Y, Liao W, Liu Q, Luo S, He M, Liang $\mathrm{G}$, Shi $\mathrm{Y}$ et al (2016) Distinct epigenomes in $\mathrm{CD}^{+} \mathrm{T}$ cells of newborns, middle-ages and centenarians. Sci Rep 6:38411

174. Sidler C, Woycicki R, Ilnytskyy Y, Metz G, Kovalchuk I, Kovalchuk $\mathrm{O}$ (2013) Immunosenescence is associated with altered gene expression and epigenetic regulation in primary and secondary immune organs. Front Genet 4:211

175. Goronzy JJ, Hu B, Kim C, Jadhav RR, Weyand CM (2018) Epigenetics of T cell aging. J Leukoc Biol 104:691-699

176. Horvath S, Raj K (2018) DNA methylation-based biomarkers and the epigenetic clock theory of ageing. Nat Rev Genet 19:371-384

177. Gross AM, Jaeger PA, Kreisberg JF, Licon K, Jepsen KL, Khosroheidari M, Morsey BM, Swindells S, Shen H, Ng CT et al (2016) Methylome-wide analysis of chronic HIV infection reveals five-year increase in biological age and epigenetic targeting of HLA. Mol Cell 62:157-168

178. Blagosklonny MV (2007) An anti-aging drug today: from senescencepromoting genes to anti-aging pill. Drug Discov Today 12:218-224

179. Salminen A, Kauppinen A, Kaarniranta K (2014) Inflammaging signaling in health span and life span regulation: next generation targets for longevity. In: Rahman I, Bagchi D (eds) Inflammation, advancing age and nutrition. Academic Press, New York, pp 323-332

180. De Maeyer RPH, van de Merwe RC, Louie R, Bracken OV, Devine OP, Goldstein DR, Uddin M, Akbar AN, Gilroy DW (2020) Blocking elevated p38 MAPK restores efferocytosis and inflammatory resolution in the elderly. Nat Immunol 21:615-625

181. Sapey E, Greenwood H, Walton G, Mann E, Love A, Aaronson N, Insall RH, Stockley RA, Lord JM (2014) Phosphoinositide 3-kinase inhibition restores neutrophil accuracy in the elderly: toward targeted treatments for immunosenescence. Blood 123:239-248

182. Le Page A, Fortin C, Garneau H, Allard N, Tsvetkova K, Tan CT, Larbi A, Dupuis G, Fülop T (2014) Downregulation of inhibitory
SRC homology 2 domain-containing phosphatase-1 (SHP-1) leads to recovery of $\mathrm{T}$ cell responses in elderly. Cell Commun Signal 12:2

183. Wang W, Wang L, Ruan L, Oh J, Dong X, Zhuge Q, Su DM (2018) Extracellular vesicles extracted from young donor serum attenuate inflammaging via partially rejuvenating aged T-cell immunotolerance. FASEB J 32:5899-5912

184. Aiello A, Farzaneh F, Candore G, Caruso C, Davinelli S, Gambino CM, Ligotti ME, Zareian N, Accardi G (2019) Immunosenescence and its hallmarks: how to oppose aging strategically? A review of potential options for therapeutic intervention. Front Immunol 10:2247

185. Keren Z, Naor S, Nussbaum S, Golan K, Itkin T, Sasaki Y, Schmidt-Supprian M, Lapidot T, Melamed D (2011) B-cell depletion reactivates $\mathrm{B}$ lymphopoiesis in the $\mathrm{BM}$ and rejuvenates the B lineage in aging. Blood 117:3104-3112

186. Fahy GM, Brooke RT, Watson JP, Good Z, Vasanawala SS, Maecker H, Leipold MD, Lin DTS, Kobor MS, Horvath S (2019) Reversal of epigenetic aging and immunosenescent trends in humans. Aging Cell 18:e13028

187. Draghiciu O, Lubbers J, Nijman HW, Daemen T (2015) Myeloid derived suppressor cells - an overview of combat strategies to increase immunotherapy efficacy. Oncoimmunology 4:e954829

188. Li C, Jiang P, Wei S, Xu X, Wang J (2020) Regulatory T cells in tumor microenvironment: new mechanisms, potential therapeutic strategies and future prospects. Mol Cancer 19:116

189. Salminen A, Kaarniranta K, Kauppinen A (2018) Phytochemicals inhibit the immunosuppressive functions of myeloid-derived suppressor cells (MDSC): impact on cancer and age-related chronic inflammatory disorders. Int Immunopharmacol 61:231-240

190. Lee M, Park CS, Lee YR, Im SA, Song S, Lee CK (2014) Resiquimod, a TLR7/8 agonist, promotes differentiation of myeloid-derived suppressor cells into macrophages and dendritic cells. Arch Pharm Res 37:1234-1240

191. Azambuja JH, Ludwig N, Braganhol E, Whiteside TL (2019) Inhibition of the adenosinergic pathway in cancer rejuvenates innate and adaptive immunity. Int J Mol Sci 20:5698

192. Kunisada Y, Eikawa S, Tomonobu N, Domae S, Uehara T, Hori S, Furusawa Y, Hase K, Sasaki A, Udono H (2017) Attenuation of $\mathrm{CD} 4{ }^{+} \mathrm{CD} 25^{+}$regulatory $\mathrm{T}$ cells in the tumor microenvironment by metformin, a type 2 diabetes drug. EBioMedicine 25:154-164

193. Qin G, Lian J, Huang L, Zhao Q, Liu S, Zhang Z, Chen X, Yue D, Li L, Li F et al (2018) Metformin blocks myeloid-derived suppressor cell accumulation through AMPK-DACH1-CXCL1 axis. Oncoimmunology 7:e1442167

Publisher's Note Springer Nature remains neutral with regard to jurisdictional claims in published maps and institutional affiliations. 